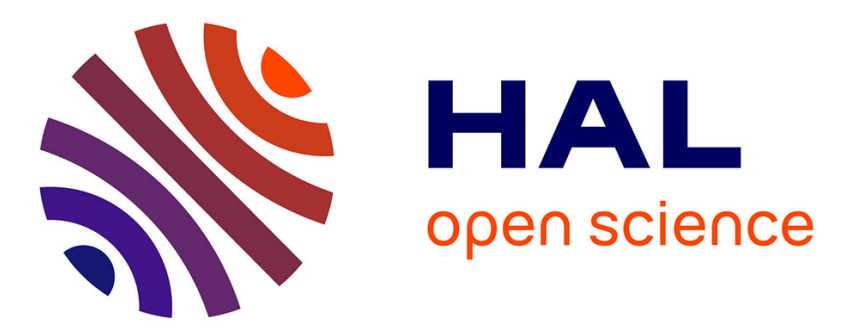

\title{
On the evolution of microstructure, texture and corrosion behavior of a hot-rolled and annealed AZ31 alloy
}

Samia Tighiouaret, Abdelkader Hanna, Hiba Azzeddine, Lyacine Rabahi, Achour Dakhouche, François Brisset, Anne-Laure Helbert, Thierry Baudin, Djamel Bradai

\section{To cite this version:}

Samia Tighiouaret, Abdelkader Hanna, Hiba Azzeddine, Lyacine Rabahi, Achour Dakhouche, et al.. On the evolution of microstructure, texture and corrosion behavior of a hot-rolled and annealed AZ31 alloy. Materials Chemistry and Physics, 2021, 267, 10.1016/j.matchemphys.2021.124598 . hal03287104

\section{HAL Id: hal-03287104 https://hal.science/hal-03287104}

Submitted on 15 Jul 2021

HAL is a multi-disciplinary open access archive for the deposit and dissemination of scientific research documents, whether they are published or not. The documents may come from teaching and research institutions in France or abroad, or from public or private research centers.
L'archive ouverte pluridisciplinaire HAL, est destinée au dépôt et à la diffusion de documents scientifiques de niveau recherche, publiés ou non, émanant des établissements d'enseignement et de recherche français ou étrangers, des laboratoires publics ou privés. 


\title{
On the evolution of microstructure, texture and corrosion behavior of a hot-rolled and annealed AZ31 alloy
}

Samia Tighiouaret ${ }^{1}$, Abdelkader Hanna ${ }^{1}$, Hiba Azzeddine ${ }^{1 *}$, Lyacine Rabahi ${ }^{2,3}$, Achour Dakhouche $^{4}$, François Brisset ${ }^{5}$, Anne-Laure Helbert ${ }^{5}$, Thierry Baudin ${ }^{5}$, Djamel Bradai ${ }^{2}$

${ }^{1}$ Department of Physics, University of Mohamed Boudiaf, M'sila, 28000, Algeria

${ }^{2}$ Laboratory of Materials Physics, Faculty of Physics, University of Sciences and Technology Houari Boumediene (U.S.T.H.B.), P.O. Box 32, El-Alia, Bab-Ezzouar, DZ-16111, Algiers, Algeria

${ }^{3}$ Research Center in Industrial Technologies CRTI. P.O. Box 64, Cheraga, Algiers, 16014, Algeria

${ }^{4}$ Inorganic Materials Laboratory, Department of chemistry, Faculty of Sciences, University of Mohamed Boudiaf, M'sila, 28000, Algeria

${ }^{5}$ Université Paris-Saclay, CNRS, Institut de Chimie Moléculaire et des Matériaux d'Orsay, 91405, Orsay, France

* Corresponding author: Dr. Hiba Azzeddine, email: hiba.azzeddine@univ-msila.dz

\begin{abstract}
The microstructure and texture evolution of an AZ31 alloy were investigated after hot rolling and subsequent annealing using electron backscatter diffraction (EBSD). First, the alloy was hot-rolled at $350{ }^{\circ} \mathrm{C}$ up to low, medium and high strain $(20,50$ and $85 \%$ of thickness reduction, respectively). The alloy samples where then annealed at $350{ }^{\circ} \mathrm{C}$ for 2,10 and 60 minutes. The effect of strain level and annealing on corrosion behavior in seawater was also evaluated using electrochemical tests. At low strain, the microstructure was characterised by the absence of twinning, mainly due to the prior thermo-mechanical history of the as-received alloy. However, various modes of twinning were observed at medium strain. At high strain, the dynamic recrystallization process resulted in a microstructure with a typical basal texture. The results demonstrate that twins are responsible for the deviation of $\{0002\}$ basal poles from normal towards the transversal direction. Annealing at $350^{\circ} \mathrm{C}$ for up to $60 \mathrm{~min}$ led to normal grain growth in all the samples. In medium and highly strained samples, the deformation texture was retained, while the low strain sample underwent noticeable changes due to the absence of dynamic recrystallization. A synergetic effect of grain refinement and texture weakening was responsible for the alloy's enhanced corrosion resistance.
\end{abstract}

Keywords: AZ31 alloy; Corrosion; Dynamic recrystallization; Static recrystallization; rolling 


\section{Introduction}

Nowadays, one of the greatest challenges for the governments and scientists communities is to find new strategies and solutions for global warming and reducing environment pollution [1]. Among possible solutions, a replacement of the fossil fuel-based energy by renewable energy [2,3], an implementation of $\mathrm{CO}_{2}$ capture and its storage (CCS) technologies [4] and a reduction of vehicle mass for transportation industries [5] have been proposed.

The low density of magnesium, which is 36 and $78 \%$ lighter than aluminium and steel, respectively, makes it the most promising candidate for lighting sources [6] and energy storage like water/seawater-activated magnesium batteries [7]. Moreover, $\mathrm{Mg}$-based alloys are attractive candidates for using in biomedical engineering as biodegradable temporary implants [8-10]. However, traditionally, Mg-based alloys comprise less than $1 \%$ of a vehicle's weight [11]. The commercial use of Mg-based alloy sheets is limited, as their hexagonal close pack (HCP) structure and the formation of a strong basal texture [12, 13] at lower temperatures result in low formability. Furthermore, Mg-based alloys generally suffer from relatively poor corrosion resistance due to their low standard electrochemical potential, which restricts their use in a variety of applications [14].

Modifying the microstructure of Mg-based alloys by thermo-mechanical processing is considered an effective way to significantly improve formability and control corrosion behavior by reducing mechanical anisotropy. Usually, this is achieved by promoting the activation of non-basal slip modes, controlling the activation of mechanical twinning, precipitation strengthening and the occurrence of the dynamic recrystallization (DRX) process [15-23]. Several DRX mechanisms have been proposed to explain the resulting microstructure and texture, such as twin-induced dynamic recrystallization (TDRX) [24], rotational dynamic recrystallization (RDRX) [25] and strain-induced boundary migration (SIBM) [25]. Furthermore, the microstructure of a deformed alloy is unstable due to the presence of deformation-induced defects, such as dislocations; hence, the material cannot be used as a final product. Therefore, post-deformation annealing treatments are often performed on processed alloys to reach a more stable state by static recrystallization and grain growth phenomena [26].

Numerous studies involving the evolution of the microstructure and texture of $\mathrm{Mg}$ based alloys during thermo-mechanical processing and subsequent annealing treatments are 
reported in the literature $[13,20,27-40]$. However, the mechanisms responsible for microstructure and texture evolution during deformation processing and recrystallization treatment are not well understood, and some reports provide controversial results. Some studies indicate that the occurrence of twin-induced dynamic recrystallization characterised by the formation of recrystallized grains inside the twins might develop a texture different from the deformation one [41, 42]. Other studies demonstrate that the orientations of dynamically recrystallized grains are the same than those of the host twins [43, 44]. Additionally, abnormal grain growth phenomena were observed in a hot-rolled AZ31 alloy during long (up to 3 days) annealing at temperatures of $260-450^{\circ} \mathrm{C}$ [31]. However, they were not observed in an AZ31 alloy after hot-rolling and subsequent annealing at $450^{\circ} \mathrm{C}$ for 7 days [45].

In addition to the nature of alloying-addition elements, many experimental parameters might control the occurrence of these mechanisms and, therefore, affect the alloy's final microstructure and texture, such as the deformation conditions (i.e., the deformation temperature, strain, and strain rate) or annealing treatment (i.e., the temperature and duration). Consequently, controlling the effect of such parameters on Mg-based alloy's performance could greatly improve the design of Mg-based alloys for large industrial applications.

Thus, the present investigation explores the effects of strain levels on the evolution of the microstructure and texture of an AZ31 (Mg-3Al-1Zn, wt.\%) alloy. The AZ31 alloy was hotrolled at $350^{\circ} \mathrm{C}$ to achieve low, medium and high strain (i.e., $20 \%, 50 \%$ and $85 \%$ thickness reduction, respectively) and subsequent annealing treatment at $350^{\circ} \mathrm{C}$ for $2-60 \mathrm{~min}$. Furthermore, the corrosion behavior of the AZ31 alloy under different thermo-mechanical conditions in real environment like seawater (collected from the Mediterranean Sea) was evaluated. Previously, a investigation limited to the effect of hot-rolling on the corrosion behavior of the same AZ31 alloy in an artificial 0.9\% $\mathrm{NaCl}$ (wt.\%) solution was reported [46]. Motivated by the challenging topics, the authors aimed to extend the investigation about the corrosion behavior of AZ31 in seawater after recrystallization and grain growth following hot-rolling. The seawater was selected as corrosion solution for the present investigation because Mg-based alloys are one of the important anode materials used in seawater activated batteries [7, 47, 48]. 


\section{Experimental procedure}

\subsection{Material}

Sheets of an AZ31 alloy with a thickness of $2.2 \mathrm{~mm}$ were kindly supplied by Magnesium Innovations Center (MagIC) in Germany. Detailed information regarding the sheet's chemical composition are presented in Table 1. The rolling experiments were conducted at a nominal temperature of $350^{\circ} \mathrm{C}$. The total reductions in thickness were 20,50 and $85 \%$, with a rolling reduction of $0.22 \mathrm{~mm} /$ pass $(10 \%$ reduction per pass). After each rolling step, the rolled samples were returned to the furnace and reheated for 10 min to regain the rolling temperature. After the final rolling pass, the samples were quenched in water. The hot-rolled AZ31 samples were then annealed at $350^{\circ} \mathrm{C}$ for 2,10 and $60 \mathrm{~min}$ in a radiation furnace, followed by water quenching.

\subsection{Microstructural and textural observations}

The microstructures and textures of the as-received, hot-rolled and annealed samples were investigated using EBSD in the RD-TD plane after mechanical and ionic polishing using a Gatan PECS II system at a high voltage of $5 \mathrm{kV}$ for $15 \mathrm{~min}$, where RD and TD designate the rolling and transversal directions, respectively. The observations were carried out using a FEG-SEM SUPRA $55 \mathrm{VP}$ scanning electron microscope operating at $20 \mathrm{kV}$. EBSD data acquisition and analysis were undertaken using a TSL orientation imaging microscopy system and $\mathrm{OIM}^{\mathrm{TM}}$ software. The scanned areas were $80 \times 80 \mu \mathrm{m}^{2}$ with a $0.2 \mu \mathrm{m}$ step size. The grainsize data were obtained using the usual clean up procedure with grain tolerance angle of $5^{\circ}$ and a minimum grain size set at 5 pixels [21, 49-52]. All datum points with a confidence index lower than 0.05 were excluded from the analysis; the confidence index quantifies the reliability of the indexed pattern [53]. Quantitative texture analysis was carried out by calculating the orientation distribution function (ODF) using MTex software [54]. The ODF was calculated using the harmonic method $(\mathrm{L}=22)$, and each orientation was modelled using a Gaussian function with a half-width of $5^{\circ}$.

\subsection{Vickers microhardness}

A Shimadzu type HMV-2 tester was used to measure the Vickers microhardness (Hv) on the RD-TD plane of the samples by using a load of $100 \mathrm{~g}\left(\mathrm{HV}_{0.1}\right)$ and a dwell time of $10 \mathrm{~s}$. The average microhardness values were calculated from at least five indentations. 


\subsection{Electrochemical testing}

Electrochemical tests were conducted using an Autolab PGSTAT302N workstation and a standard three-electrode cell. The samples were embedded in an epoxy resin to isolate a $1 \mathrm{~cm}^{2}$ area from the non-studied surfaces. The open-circuit potential (OCP) was measured for at least $60 \mathrm{~min}$ for all samples in a seawater solution (collected from the Mediterranean Sea) at ambient temperature. Impedance measurements were subsequently performed using a sinusoidal potential signal with an amplitude of $10 \mathrm{mV}$ in the frequency range of $10^{-2}-10^{5} \mathrm{~Hz}$. Experimental curves were fitted using Zview software. As-received sample was immersed in seawater for $3 \mathrm{~h}$, followed by corrosion morphology analysis using a scanning electron microscope (SEM, FEG-SEM ZEISS Gemini) equipped with an energy dispersive spectrometry (EDS) system in backscatter (BSE) mode at $15 \mathrm{kV}$.

\section{Results}

\subsection{Microstructure and texture of the as-received AZ31 alloy}

Figs. 1a and 1b show the microstructure of the as-received AZ31 alloy in terms of orientation imaging micrographs in an inverse pole figure (ND-IPF) mode and grain orientation spread (GOS) maps. The white and black lines in the ND-IPF map are ascribed to low-angle grain boundaries (LAGBs, $2-15^{\circ}$ ) and high-angle grain boundaries (HAGBs, $>15^{\circ}$ ), respectively. The GOS approach implemented in OIM software allows the net separation of recrystallized and deformed grains. The GOS parameter is defined as the average deviation between the orientation of each point in the grain and the average orientation of the grain [55]. Usually, the grains were considered as recrystallized in $\mathrm{Mg}$ based alloys if the GOS parameter varied between $1^{\circ}$ and $2^{\circ}[49,56,57]$. As shown, most of the grains were deformed and contained a high amount of LAGBs. In addition, some deformation twins could be observed in the microstructure. The black zones present in the microstructure indicated some highly deformed areas of the sample. The average grain size was found to be $16.1 \pm 0.6 \mu \mathrm{m}$. The recalculated $\{0002\}$ pole figure shown in Fig. 1c indicates that the as-received alloy exhibited a strong (13 multiple random distributions, mrd) typical basal texture where the $\{0002\}$ crystallites planes are oriented parallel to the sheet plane [58].

\subsection{Microstructure and texture of the hot-rolled and annealed AZ31 alloy}

Fig. 2 presents an ND-IPF map of the AZ31 alloy after hot rolling up to 20, 50 and $85 \%$ thickness reduction and subsequent annealing at $350^{\circ} \mathrm{C}$ for 2,10 and $60 \mathrm{~min}$. The 
evolution of the grain size and fraction of HAGBs as a function of annealing time in the hotrolled AZ31 samples are shown in Fig. 3. As expected, the grain size decreased with increasing thickness reduction. The grain size of 20,50 and $85 \%$ hot-rolled samples were $14.9 \pm 0.4,6.9 \pm 0.3$ and $4 \pm 0.3 \mu \mathrm{m}$, respectively. A heterogeneous microstructure could be observed in the annealed samples for 2 min, with the presence of a high fraction of LAGBs and twins, especially in the $20 \%$ and $50 \%$ hot-rolled samples. The microstructures became more homogenous with increasing annealing time, and no abnormal grain growth was evidenced. The grain size of the $20 \%$ hot-rolled sample exhibits a continuous decrease with annealing time, reaching a value of $8.5 \pm 0.4 \mu \mathrm{m}$ after $60 \mathrm{~min}$. However, both $50 \%$ and $85 \%$ hot-rolled samples show a decrease in the grain size after annealing for $2 \mathrm{~min}$, increasing after $10 \mathrm{~min}$ and then slight increasing $(6.6 \pm 0.6$ and $5.6 \pm 0.4 \mu \mathrm{m}$ for the $50 \%$ and $85 \%$ hot-rolled samples, respectively).

Fig. $3 \mathrm{~b}$ shows that the HAGBs fraction of the deformed samples was between 25 and $35 \%$ whatever the hot-rolled thickness reduction. Annealing treatment caused an increase of the high-angle grain boundaries fraction of all samples indicating the occurrence of a recrystallization process. The HAGBs fraction after annealing for 60 min was found to be $77.3,80$ and $82 \%$ for the 20,50 and $85 \%$ hot-rolled samples, receptively.

Fig. 4 shows the variation in microhardness as a function of the annealing time of the hot-rolled AZ31 alloy up to 20,50 and $85 \%$ thickness reduction. It should be noted that the microhardness of the as-received AZ31 alloy was equal to $72.5 \pm 1.5 \mathrm{Hv}$. As expected, the $85 \%$ hot-rolled sample exhibited the highest $\mathrm{Hv}$ value $(86.1 \pm 1.2 \mathrm{Hv})$, followed by the $50 \%$ hot-rolled sample $(79.5 \pm 1.5 \mathrm{Hv})$ and then $20 \%$ hot-rolled sample $(74 \pm 1.6 \mathrm{Hv})$. The microhardness values decreased with increasing annealing time due to static recrystallization and grain growth processes.

Figs. 5 and 6 present the GOS maps and evolution of recrystallization fractions of the hot-rolled samples as a function of annealing time, respectively. The recrystallized grain fraction increased with increasing annealing time for all deformed samples. Furthermore, the recrystallized fraction of the 60 min annealed $20 \%$ hot-rolled sample was lower $(87.3 \%)$ than the other annealed samples (93\%). Moreover, the rate of recrystallization increased with increasing thickness reduction. The recrystallization fraction of the $20 \%$ hot-rolled sample was stable after annealing for $2 \mathrm{~min}$ and then increased with increasing annealing time. In contrast, the recrystallization fraction after 2 min of annealing increased rapidly for the 50\% and $85 \%$ hot-rolled samples. This finding might be related to stored energy increasing along 
with the strain level. The evolution of deformation and the recrystallization texture is presented in Fig. 7, and the strengthening of the texture as a function of annealing time was evaluated using the following equation [59]:

$$
I=\frac{1}{8 \pi^{2}} \int_{G} f^{2}(g) \cdot d g
$$

where $I$ is the texture index, $f(g)$ is the ODF intensity at $g$ orientation and $G$ is the Euler space.

The strengthening of the basal texture decreased with increasing thickness reduction, as shown in Fig. 8. In the $20 \%$ hot-rolled sample, the basal texture remained sharp after annealing for $2 \mathrm{~min}$ (17 $\mathrm{mrd})$ and seemed to weaken with increasing annealing time (8.1 mrd after $60 \mathrm{~min}$ ). Consequently, the texture index of the sample continuously decreased with increasing annealing time, as shown in Fig. 8. Furthermore, the distributions of $\{0002\}$ poles changed with increasing annealing time and were more distributed towards TD. Such texture modifications during annealing treatment could be an indication of a discontinuous recrystallization mechanism [60]. The distribution of $\{0002\}$ poles towards TD was already developed in 50\% hot-rolled sample as shown in Fig. 7. No changes in the texture of the 50\% hot-rolled sample were observed with increasing annealing time, except that the texture index increased with annealing for $10 \mathrm{~min}$ and then decreased after $60 \mathrm{~min}$ of annealing. Interestingly, the texture index of both the $20 \%$ and $50 \%$ hot-rolled samples was similar after annealing for 10 and $60 \mathrm{~min}$. The typical basal texture formed after $85 \%$ thickness reduction was also retained during annealing treatment. However, Fig. 8 demonstrates that the texture strengthening of the $85 \%$ hot-rolled sample increased with increasing annealing time.

\subsection{Corrosion behavior of AZ31 alloy in seawater}

Fig. 9a shows Nyquist plots of the as-received, hot-rolled and annealed for $60 \mathrm{~min}$ samples after immersion in seawater for $1 \mathrm{~h}$. Notably, all samples show the presence of one capacitive loop in the high-frequency region, followed by an induction loop in the lowfrequency region. The similarities in the Nyquist curves indicate that the different thermomechanically processed AZ31 alloy samples underwent similar corrosion mechanisms. However, differences in the evolution of capacitance diameters as a function of sample conditions indicate differences in the corrosion rate. The capacitive loop in the high-frequency region is related to the formation process of the corrosion product on the solution/metal surface, while the presence of an inductance loop in the low-frequency region is characteristic of pitting corrosion and dissolution of the protective film [61]. 
Fig. 9a shows that the diameter of the capacitive loop increased with increasing thickness reduction. Annealing for 60 min seemed to improve the deformed AZ31 alloy's corrosion resistance, as demonstrated by the increase in the diameter. However, the corrosion resistance of the annealed $85 \%$ hot-rolled sample was lower than that of the deformed one. To further explore the effect of deformation and annealing treatment on the corrosion mechanism of the AZ31 alloy, an electrochemical equivalent circuit was suggested, as shown in Fig. 9b. The corresponding fitting parameters of the Nyquist curves are presented in Table 2.

In the proposed equivalent circuit, $R_{s}, R_{f}, R_{c t}$ and $R_{L}$ are the solution, film, charge transfer and inductance resistance, respectively. $C P E_{f}$ is a constant phase element resulting from the formation of corrosion product on the sample surface. The presence of $C P E_{d l}$ is due to the formation of a double layer and a charge transfer reaction between the metal interface and the solution. $L$ is an inductance parameter that expresses the occurrence and amount of pitting corrosion [61]. Polarisation resistance can be calculated using the different resistances appearing in the equivalent circuit, as follows [62]:

$$
R_{p}=R_{s}+R_{f}+\frac{R_{c t} R_{L}}{R_{c t}+R_{L}}
$$

The values of $R_{p}$ are presented in Table 2 . The AZ31 alloy's $\mathrm{R}_{p}$ values increased along with the imposed strain, and the annealing treatment improved corrosion resistance. The $R_{p}$ values increased from 109 to $223.6 \Omega . \mathrm{cm}^{2}$ and from 161 to $264.13 \Omega . \mathrm{cm}^{2}$ after annealing the $20 \%$ and $50 \%$ samples, respectively. Although the annealed $85 \%$ sample $\left(96.9 \Omega . \mathrm{cm}^{2}\right)$ showed a lower value than the deformed one $\left(174.8 \Omega . \mathrm{cm}^{2}\right)$, the corrosion resistance of the annealed $85 \%$ sample was higher than that of the as-received one $\left(76.3 \Omega . \mathrm{cm}^{2}\right)$.

The corrosion morphology of the as-received AZ31 alloy after immersion in seawater for $3 \mathrm{~h}$ is presented in Fig. 10 with the mean of SEM micrographs in backscatter mode at low and high magnifications. The corresponding EDS results (in wt.\%) in analyzed points numbered 1, 2, 3 and 4 are also shown in Fig. 10. Obviously, the morphology of the surface was not uniform, and a white-coloured compound formed and engulfed the sample surface. An EDS analysis of this white compound (points 1 and 2) demonstrated the presence of high content of $\mathrm{O}(\sim 52 \%)$ and $\mathrm{Mg}(\sim 41 \%)$, indicating the formation of a magnesium hydroxide $\mathrm{Mg}(\mathrm{OH})_{2}$ compound rather than $\mathrm{MgO}$ oxide. The $\mathrm{MgO}$ was found to gradually transform into $\mathrm{Mg}(\mathrm{OH})_{2}$ with increasing immersion time [46]. Moreover, the thickness of $\mathrm{MgO}$ was found to decrease with increasing $\mathrm{Al}$ content in $\mathrm{Mg}$ - $\mathrm{Al}$ alloys [63]. A relatively high amount of $\mathrm{Cl}$ ( $3 \%$ ) was also observed in these areas. The corrosion morphology also showed the presence of 
cracks (as shown by arrows), mainly due to the dehydration of the corrosion product. The high resolution of the region delimited by the yellow square shows the presence of small 'mushrooms-like' morphology. Similar morphologies were reported in an $\mathrm{Mg}-\mathrm{RE}$ alloy corroded in a 3.5\% $\mathrm{NaCl}$ solution [64]. The EDS analysis of point 3 and 4 indicates the presence of $\mathrm{Mg}(\mathrm{OH})_{2}$ compound. Interestingly, the amount of $\mathrm{Cl}$ in these zones was lower than for zones 1 and 2 (white compound). The high magnification of the red-square region shows the typical corrosion morphology of needle-like particles frequently reported in $\mathrm{Mg}$ based alloys $[64,65]$.

\section{Discussion}

The present study aimed to investigate the effect of hot-rolling and recrystallization on the evolution of the microstructure, texture and corrosion behavior in AZ31 alloy.

\subsection{Deformation microstructure and texture}

As shown in Figs. 2 and 3, grain size decreased with increasing strain. However, the HAGBs first decreased with increasing strain at 50\% thickness reduction (24.6\%) and then increased at $85 \%$ thickness reduction (31.8\%), mainly due to the occurrence of DRX. Fig. 5 and the evolution of recrystallized fraction shown in Fig. 6, demonstrate that the AZ31 alloy underwent DRX during hot working only at medium and high strain (i.e., 50 and 85\% thickness reduction). The absence of DRX in the $20 \%$ hot-rolled sample may be explained by the deformation strain level being insufficient to cause DRX. In fact, the microstructure looks similar to the as-received AZ31 alloy, as shown in Fig. 1a.

The kernel average misorientation (KAM) approach is commonly used to estimate the distribution of strain and dislocation density in individual measured points [66]. Generally, the KAM method allows quantifying the average misorientation between a given point and its nearest neighbours belonging to the same grain. Fig. 11 presents the KAM maps and corresponding distributions in the hot-rolled AZ31 alloy for the three thickness reductions. The KAM was calculated using third-neighbor distance and $5^{\circ}$ as the maximum misorientation angle. Several grains in the $20 \%$ hot-rolled sample were blue in colour with an assigned misorientation of less than $1^{\circ}$ and were considered un-deformed regions. The strain mainly accumulated near the grain boundaries and specifically LAGBs (green colour). The KAM level increased $\left(\mathrm{KAM}_{\mathrm{avg}}=2.13^{\circ}\right)$ after $50 \%$ thickness reduction due to the deformation process and increased dislocation density. Despite increasing the thickness reduction up to $85 \%$, the mean $\mathrm{KAM}$ value seemed to remain stable $\left(\mathrm{KAM}_{\mathrm{avg}}=2.11^{\circ}\right)$. Additionally, the $85 \%$ 
hot-rolled sample contains some blue-coloured grains (low KAM value), mostly due to the occurrence of DRX, as shown in GOS map (Fig. 5).

However, microhardness values increased (Fig. 4) between 50\% and 85\% thickness reduction, indicating a continuous increase in dislocation density. Dislocations that accumulate in the deformed microstructure are commonly categorised into geometrically necessary dislocations (GNDs) and statistically stored dislocations (SSDs). The KAM approach can only estimate the density of GNDs [67] while microhardness measurements allow both types to be estimated [68]. It has been reported that GNDs are responsible for the increase in stored energy in the initial stage of deformation, and their contribution subsequently decreases due to the occurrence of DRX. However, the contribution of SSDs increases along with increasing strain to ensure deformation accommodation [69].

Increasing strain generates new orientations, as shown in the ND-IPF map (Fig. 2) and the evolution of deformation texture (Fig. 7). At low strain (20\% thickness reduction), the typical basal texture was observed, as the $\{0002\}$ poles were parallel to the sheet plane. The high intensity ( $18 \mathrm{mrd}$ ) was mainly due to poor grain statistics, as shown in the ND-IPF map (Fig. 2). Otherwise, for the other hot-rolled samples, texture intensity should increase along with increasing thickness reduction. Texture sharpening upon increasing thickness reduction is often reported in rolled Mg-based alloys [70-72]. Texture development is usually strongly related to the deformation mechanisms [73]. At medium strain (50\% thickness reduction), the $\{0002\}$ basal poles are more distributed towards TD. The change in the texture may be related to the presence of mechanical twinning [27].

It is known that the formation of twins during deformation strongly affects the resulting texture by changing the orientation of the lattice structure [74, 75]. Close inspection of the ND-IPF maps (Fig. 2) clearly indicates that the twins are more frequently evidenced in the $50 \%$ hot-rolled sample than in other samples. The fractions of common twin modes (i.e., $\{10 \overline{1} 2\}$ extension twin, $\{10 \overline{1} 1\}$ contraction twin and $\{10 \overline{1} 1\}-\{10 \overline{1} 2\}$ or $\{10 \overline{1} 3\}-\{10 \overline{1} 2\}$ double twins) in the hot-rolled samples are listed in Table 3. Unexpectedly, the $20 \%$ hotrolled sample presented a very low fraction of twins, especially $\{10 \overline{1} 2\}$ extension twins. The presence of twins was evidenced by optical microscope in the AZ31 alloy under similar conditions (hot-rolling up to $20 \%$ thickness reduction) [46]. Further, optical microscope observations demonstrated the formation of twins only after 5\% thickness reduction in an AZ31 alloy sample hot-rolled at $300^{\circ} \mathrm{C}$ [44]. The absence of twins at low strain in the presently studied alloy might be related to the as-received microstructure. Indeed, the asreceived AZ31 alloy exhibited a deformation microstructure. Twin generation was retarded by 
pre-existing dislocations in the as-received alloy, which might increase the energy barriers for twin nucleation [76]. The number of twins increased along with strain, as shown in the 50\% hot-rolled sample. All twin modes were present, except contraction twins (1.3\%). It was demonstrated that contraction twin can rapidly transformed into double twin during deformation processing in Mg-0.41Dy (wt.\%) alloy [50, 51] and AZ61 alloy [77]. A higher fraction of double $22^{\circ}<11 \overline{2} 0>$ twins was also observed in the $85 \%$ hot-rolled sample which confirm the finding in Mg-0.41Dy and AZ61 alloys [51, 77].

The decrease in twin fractions in the $85 \%$ hot-rolled sample could be correlated with the decrease in grain size $[72,78]$. The generation of twins is hindered with decreasing grain size because the distribution of stress in fine grains is unfavourable for twin activation, while in coarse grains, it is considerably more advantageous [72].

Fig. 12 presents a selected region of the ND-IPF map (Fig. 2) of the 50\% hot-rolled sample containing different twin modes. Different twin morphologies were observed in the hot-rolled sample. The misorientation profile along segments A to B indicates a step-like morphology, which form from double twins. A similar twin structure has been reported in several Mg-based alloys [35, 73]. The development of this twin step is governed by homogeneity in the stress distribution and strain level [35]. The misorientation profile along segments $\mathrm{C}$ to $\mathrm{D}$ shows different types of twins. The corresponding $\{0002\}$ pole figure indicates that different mechanical twins were able to change or create different orientations from the typical basal texture. The extension twin caused a rotation of about $86^{\circ}$ in the $\{0002\}$ plane, leading to the formation of $\{0002\} / / R D$. In contrast, both contraction and double twins caused a deviation of $\{0002\}$ basal poles towards TD.

In the literature, it has been reported that weakening of the basal texture is caused by the activation of twins and non-basal slip systems (i.e., $<a>$ prismatic and $<\mathrm{c}+\mathrm{a}>$ pyramidal $\operatorname{slip}($ [79]. Indeed, the activation of prismatic $<a>$ slip contributed to the deviation of basal poles about $20-40^{\circ}$ from ND towards TD [80]. This corroborates the texture of the $50 \%$ hotrolled sample. However, a typical basal texture developed with increasing strain in the $85 \%$ hot-rolled sample. The decrease in the twin faction and activation of a $<c+a>$ pyramidal slip in the deformed sample could explain the disappearance of deviation towards TD. It has been demonstrated by visco-plastic self-consistent (VPSC) simulation that the activation of a $<\mathrm{c}+\mathrm{a}>$ pyramidal slip causes the splitting of the basal pole towards RD [70]. Moreover, it was expected that the $\langle\mathrm{c}+\mathrm{a}\rangle$ pyramidal slip would be more activated in the hot-rolled $85 \%$ sample since it is assumed that its activation increases along with thickness reduction [71]. 
The variation in texture as a function of thickness reduction is also commonly related to the occurrence of DRX. As shown in Figs. 5 and 6, the fraction of dynamic recrystallized grains increased along with thickness reduction. The textures of deformed and recrystallized grains of the AZ31 alloy hot-rolled to $50 \%$ and $85 \%$ thickness reduction are separately presented in Fig. 13 by means of recalculated $\{0002\}$ pole figures. The orientations of recrystallized grains in the $50 \%$ hot-rolled sample differed from the deformed ones. The formation of an $\{0002\} / / R D$ orientation is indicative of a twin-induced DRX mechanism [24]. In fact, the twins contain high levels of stored energy and can act as favourable sites for DRX. Some reports demonstrated that such mechanism resulted in similar orientations than the host twin $[43,44]$. However, the orientations of recrystallized and deformed grains were similar for the $85 \%$ hot-rolled sample. The difference in the orientation of dynamically recrystallized grains of the two hot-rolled samples suggests different nucleation behaviors during DRX. The change in $50 \%$ hot-rolled sample recrystallized grain orientations could be related to its high deformation microstructure heterogeneity, which made a wide variety of orientations available for recrystallization nucleation. In the $85 \%$ hot-rolled sample, the orientation of dynamically recrystallized grains seems to be limited to the basal orientation $\{0002\} / / N D$ initially present in the deformed microstructure.

\subsection{Recrystallization microstructure and texture}

The annealing treatment at $350^{\circ} \mathrm{C}$ for 2-60 min resulted in normal grain growth for all hot-rolled samples, as shown in Figs. 2 and 3. The small variation in grain-size values as a function of annealing time (Fig. 3a) indicates an appreciable grain refinement when compared to the as-received state. However, the evolution of HAGBs as a function of annealing time (Fig. 3b) shows that even after annealing for $60 \mathrm{~min}$, the microstructure contained LAGBs (25\%, 20\% and $18 \%$ for $20 \%, 50$ and $85 \%$ hot-rolled samples, respectively) and may indicate that recrystallization was incomplete. Actually, the presence of LAGBs was attributed to the basal texture, which resulted in low grain boundary misorientation between grains with similar orientations.

The evolution of recrystallized fractions as a function of annealing time indicates that the $20 \%$ hot-rolled sample needed a 2 min incubation time (Fig. 6). The incubation time decreased with increasing thickness reduction. In fact, the decrease of the thickness reduction by rolling results in an increase of the deformation features such as dislocation, twins and/or shear bands which act as preferred nucleation sites for recrystallization, thereby increasing the recrystallization rate. Moreover, a close analysis of the GOS maps of hot-rolled samples 
suggests that the DRX fraction increased with increasing thickness reduction. These dynamically recrystallized grains worked as a 'precursor' that reduced the incubation time for static recrystallization during annealing. Grain size was much smaller in the $85 \%$ hot-rolled sample compared to the other hot-rolled samples, which is consistent with the statement that increasing the recrystallization rate prevents grain coarsening [33].

Furthermore, annealing the low-strained sample (20\% thickness reduction) caused the spreading of basal poles from ND towards TD, while no changes in the recrystallization texture were observed in the medium- and high-strained samples (Fig. 7). Fig. 14 presents the evolution of the recalculated $\{0002\}$ pole figure for the deformed and recrystallized grains as a function of the annealing time of the hot-rolled AZ31 alloy. The texture of recrystallized grains in the $20 \%$ hot-rolled sample differs from the deformed one while the textures of the recrystallized grains in 50 and $85 \%$ hot-rolled samples are very similar to the deformed ones. The particular $\{0002\} / /$ RD orientation found in the DRX grains of the 50\% hot-rolled sample (Fig. 13) disappeared upon annealing. It has been suggested that grains with a $\{0002\}$ basal orientation are prone to higher nucleation rates when compared to other orientations, which makes them more likely to vanish; thus, the $\{0002\}$ basal orientation dominates the recrystallization texture [32]. Consequently, the occurrence of DRX in the 50 and $85 \%$ hotrolled samples prevented texture changes during static recrystallization. Furthermore, the increased texture index of both 50 and $85 \%$ rolled samples during annealing treatment indicates that DRX caused a net sharpening of the recrystallization texture, especially in the $85 \%$ hot-rolled sample.

In the literature, several parameters and phenomena have been associated with the variation in the recrystallization texture, including deformation heterogeneities [81], particlestimulated nucleation of recrystallization (PSN) [82], solute drag [83] and abnormal grain growth [84]. PSN and abnormal grain growth should not be responsible for the texture change in the present alloy since neither was clearly evidenced by EBSD analysis. However, the effect of solute ( $\mathrm{Al}$ and $\mathrm{Zn}$ ) elements on grain boundary mobility should be excluded since only one AZ31 alloy (with fixed composition) was used in the present study.

DRX could be responsible for texture changes in the hot-rolled sample at low strain (20\% thickness reduction). At low strain, the sample did not undergo DRX, unlike the samples hot rolled at medium and high strain. The low deformation strain could be insufficient to initiate DRX. It was observed that recrystallization texture weakening in the hot-rolled AZ31 alloy was more effective when nө DRX did not occur [33]. The incubation time of $2 \mathrm{~min}$ indicates that the $20 \%$ hot-rolled sample could recover before the 
recrystallization process. The recovery process caused the annihilation of SSDs, which allowed GNDs to transform into cell boundaries, leading to the formation of sub-grains with widespread basal pole orientations. In addition, the low strain level might increase the possibility of a wide range of orientations to nucleate and, therefore, result in dispersion of the texture (see Fig. 2).

\subsection{Effect of microstructure and texture variation on corrosion behavior}

Corrosion morphology and EDS analysis of the corroded surface of the as-received AZ31 alloy (Fig. 10) revealed the formation of $\mathrm{Mg}(\mathrm{OH})_{2}$, a typical corrosion product formed when the Mg-based alloys are immersed in an aqueous solution. The formation of $\operatorname{Mg}(\mathrm{OH})_{2}$ compounds is often accompanied by hydrogen evolution based on the following equations [85]:

$$
\begin{gathered}
\mathrm{Mg} \rightarrow \mathrm{Mg}^{2+}+2 \mathrm{e}^{-} \\
\mathrm{H}_{2} \mathrm{O}+2 \mathrm{e}^{-} \rightarrow 2 \mathrm{OH}^{-}+\mathrm{H}_{2} \\
\mathrm{Mg}+\mathrm{H}_{2} \mathrm{O} \rightarrow \mathrm{Mg}(\mathrm{OH})_{2}+\mathrm{H}_{2}
\end{gathered}
$$

The Nyquist plots and fitted parameters shown in Fig. 9 and Table 3 demonstrate that the AZ31 alloy's corrosion resistance increased along with thickness reduction. Based on the evolution of the deformation microstructure, especially in the $85 \%$ hot-rolled sample, it can be concluded that improved corrosion resistance may be due to two main reasons: (i) decreased grain size and (ii) occurrence of DRX. Several reports have demonstrated that grain refinement improves the corrosion resistance of many processed Mg-based alloys [28, 86-88]. Decreasing grain size means increasing the fraction of grain boundaries, which ensures uniform corrosion product distribution across the sample surface and, consequently, decreased dissolution of the $\mathrm{Mg}$ matrix. It was recently demonstrated that galvanic corrosion preferentially occurs in the deformed region rather than in the dynamically recrystallized one [89]. This finding is consistent with the present results, where the $85 \%$ hot-rolled sample shows the highest fraction of DRX (Figs. 5 and 6).

However, it has previously been reported that the corrosion resistance of an asreceived AZ31 sample was better than that of hot-rolled to 20 and $50 \%$ thickness in $0.9 \%$ $\mathrm{NaCl}$ solution [46]. Moreover, severe plastic deformation processing via high pressure torsion (HPT) of AZ31 and ZK60 alloys showed no significant effect on corrosion behavior when testing in a $3.5 \% \mathrm{NaCl}$ solution [90]. The difference in corrosion behavior in the present study 
could be attributed to the nature of the immersion solution. It is expected that an artificial $\mathrm{NaCl}$ solution would be more aggressive than seawater. On average, seawater has a salinity of approximately $3.5 \%$ and a relative ion concentration as follows: magnesium $0.129 \%$, chlorine $1.95 \%$, potash $0.038 \%$, bromine $0.067 \%$, sodium $1.077 \%$ and calcium $0.0412 \%$ [91]. In addition to the presence of these different elements, seawater contains pollutants and decomposed organic matter, which affect the corrosion behavior of the alloy. The corrosion rate of austenitic stainless steel was found to be lower in seawater than in artificial $3.5 \% \mathrm{NaCl}$ solution [92]. Recently, it was evidenced that alloys with small grain sizes corrode more easily in aggressive corrosion media [93].

Fig. 9 and Table 3 show that annealing treatment for $60 \mathrm{~min}$ at $350^{\circ} \mathrm{C}$ also led to an increased corrosion resistance of all hot-rolled samples except the $85 \%$ hot-rolled sample. It is well expected that the deformed sample is likely to be more prone to corrosion than the annealed one due to more stored strain energy in the form of deformation features (dislocations, twins...). However, it must be noted that the annealed $85 \%$ hot-rolled sample exhibited a good corrosion resistance compared to the as-received, 20 and 50\% hot-rolled samples. This behavior could be related to the smaller grain size of the annealed $85 \%$ hotrolled sample $(5.6 \pm 0.4 \mu \mathrm{m})$ than as-received $(16.1 \pm 0.6 \mu \mathrm{m}), 20 \%(14.9 \pm 0.4 \mu \mathrm{m})$ and $50 \%$ hotrolled $(6.9 \pm 0.3 \mu \mathrm{m})$ samples (Fig. 3). It can be speculated that the decrease of the corrosion resistance of the annealed $85 \%$ hot-rolled sample could be attributed to the strengthening of the basal texture during annealing as demonstrated in Fig. 8.

The results reveal that the annealed 50\% hot-rolled sample showed excellent corrosion resistance. This could be associated with an optimal combination of grain refinement and texture weakening. Actually, the grains size of $50 \%$ hot-rolled sample decreases from $8 \pm 0.3$ $\mu \mathrm{m}$ to $6.6 \pm 0.3 \mu \mathrm{m}$ during annealing for $60 \mathrm{~min}$. In addition, the texture strength shown in Fig. 8 demonstrated that the texture of the 50\% hot-rolled sample weaken after annealing for 60 min. Similar observations can be noticed for $20 \%$ hot-rolled sample which confirm that combination of grain refinement and texture weakening help to improve the corrosion resistance of the materials. It has been reported that grains of an AZ31 alloy with a $\{0002\}$ basal orientation are less corroded in $3.5 \% \mathrm{NaCl}$ solution than grains with a $\{10 \overline{1} 0\}$ prismatic orientation [94]. The present study indicates that the deviation of $\{0002\}$ basal pole towards TD observed in the annealed 50 and also $20 \%$ hot-rolled samples could be responsible for improved corrosion resistance when compared to the typical basal texture observed in the annealed $85 \%$ hot-rolled sample. In future research activities, it would be interesting to further 
investigate the effect of $\{0002\}$ basal pole deviation and its ideal position on the corrosion behavior of an AZ31 alloy. In addition, it will be very interesting to extent our investigations to highlight the existence of any limit or threshold value of grain size for enhancing the corrosion resistance in seawater.

Indeed, as remarkably stated in ref. [2], the industrialization is criticized as the major source of releasing toxic contaminating agents into the aquatic ecosystems. The corrosion products resulting from used source batteries may also be classified as hazardous and undesirably compromise the quality of water and manifests a serious menace to human beings and aquatic creatures.

Accordingly, the present results could be helpful for optimum conditions for controlling corrosion rate and increasing the use of $\mathrm{Mg}$-based alloys in various structural applications.

\section{Conclusions}

The microstructure and texture of an AZ31 alloy were investigated after hot rolling at $350^{\circ} \mathrm{C}$ up to $20 \%, 50 \%$ and $85 \%$ thickness reduction and subsequent annealing at $350^{\circ} \mathrm{C}$ for 2-60 min. Furthermore, the effect of hot rolling and static recrystallization on the corrosion behaviour of AZ31 alloy in seawater was evaluated. The main conclusions can be drawn as followed:

- The deformation microstructure depends strongly on the amount of imposed strain. At low strain (20\% thickness reduction), a low fraction of twins was observed, likely due to the deformation state of the as-received alloy. A high fraction of $\{10 \overline{1} 2\}$ extension twins was observed at medium strain (50\% thickness reduction). However, at the high strain ( $85 \%$ thickness reduction) the microstructure was characterised by the occurrence of DRX.

- The presence of twins and DRX strongly affected the deformation texture. The presence of twins causes the deviation of basal texture towards TD, while DRX exhibits a strong typical basal texture.

- Annealing at $350^{\circ} \mathrm{C}$ for up to $60 \mathrm{~min}$ led to normal grain growth in all hotrolled samples. The deformation texture was retained in annealed $50 \%$ and $85 \%$ hotrolled samples, while a net change in the recrystallization texture was observed after 2 min of annealing in the $20 \%$ hot-rolled sample. This behavior was attributed to the absence of DRX in the latter sample. 
- The corrosion resistance of the AZ31 alloy in seawater was improved with increasing thickness reduction due to the decrease in the grain size and the occurrence of DRX. While, the improvement of the corrosion resistance in annealed samples was more related to the weakening of the texture.

- A balance between grain refinement and texture weakening can help to design new generation of Mg-based alloy with optimum properties.

\section{Acknowledgments}

The authors are grateful to Dr Ing. Norbert Hort and Dr DietmarLetzig of the Magnesium Innovations Center (MagIC) in Germany for kindly providing the AZ31 alloy. The authors would also like to thank Dr Kamel Tirsatine for his help with the rolling process. This work was supported by the PRFU national project under grant agreement no. B00L02UN280120180005.

Funding: "This research was funded by PRFU national project under Grant Agreement No. B00L02UN280120180005".

Conflicts of Interest: The authors declare no conflict of interest.

Data Availability: The raw/processed data required to reproduce these findings cannot be shared at this time as the data also forms part of an ongoing study.

\section{References}

[1] T. Rasheed, S. Shafi, M. Bilal, T. Hussain, F. Sher, K. Rizwan, Journal of Molecular Liquids, 318 (2020) 113960. DOI: https://doi.org/10.1016/j.molliq.2020.113960.

[2] S. Sehar, F. Sher, S. Zhang, U. Khalid, J. Sulejmanović, E.C. Lima, Journal of Molecular Liquids, 313 (2020) 113494. DOI: https://doi.org/10.1016/j.molliq.2020.113494.

[3] T. Rasheed, A.A. Hassan, F. Kausar, F. Sher, M. Bilal, H.M.N. Iqbal, TrAC Trends in Analytical Chemistry, 132 (2020) 116066. DOI: https://doi.org/10.1016/j.trac.2020.116066.

[4] F. Sher, S.Z. Iqbal, S. Albazzaz, U. Ali, D.A. Mortari, T. Rashid, Fuel, 282 (2020) 118506. DOI: https://doi.org/10.1016/j.fuel.2020.118506.

[5] K.U. Kainer, Challenges for Implementation of Magnesium into More Applications, in: A. Singh, K. Solanki, M.V. Manuel, N.R. Neelameggham (Eds.) Magnesium Technology 2016, Springer International Publishing, Cham, 2016, pp. 5-6.

[6] A. Luo, Fundamentals of Magnesium Alloy Metallurgy, (2013) 266-316. DOI: 10.1533/9780857097293.266. 
[7] D. Lowy, B. Mátyás, DRC Sustainable Future: Journal of Environment, Agriculture, and Energy, 1 (2019) 1-6. DOI: 10.37281/DRCSF/1.1.1.

[8] T.-C. Wu, Y.-H. Ho, S.S. Joshi, R.S. Rajamure, N.B. Dahotre, Lasers in Medical Science, 32 (2017) 797-803. DOI: 10.1007/s10103-017-2174-1.

[9] J.Z. Lu, S.S. Joshi, M.V. Pantawane, Y.-H. Ho, T.-C. Wu, N.B. Dahotre, Materials Science and Engineering: C, $105 \quad$ (2019) 110028. DOI: https://doi.org/10.1016/j.msec.2019.110028.

[10] H. Azzeddine, A. Hanna, A. Dakhouche, B. Luthringer-Feyerabend, Journal of Magnesium and Alloys, (2020). DOI: https://doi.org/10.1016/j.jma.2020.09.003.

[11] S. Kleinbaum, in: V.V. Joshi, J.B. Jordon, D. Orlov, N.R. Neelameggham (Eds.) Magnesium Technology 2019, Springer International Publishing, Cham, 2019, pp. 13-14.

[12] B.L. Mordike, T. Ebert, Materials Science and Engineering: A, 302 (2001) 37-45. DOI: https://doi.org/10.1016/S0921-5093(00)01351-4.

[13] H. Azzeddine, D. Bradai, International Journal of Materials Research, 103 (2012) 13511360. DOI: $10.3139 / 146.110768$.

[14] A. Atrens, G.-L. Song, M. Liu, Z. Shi, F. Cao, M.S. Dargusch, Advanced Engineering Materials, 17 (2015) 400-453. DOI: 10.1002/adem.201400434.

[15] M.R. Barnett, Journal of Light Metals, 1 (2001) 167-177. DOI: https://doi.org/10.1016/S1471-5317(01)00010-4.

[16] K. Matsubara, Y. Miyahara, Z. Horita, T.G. Langdon, Acta Materialia, 51 (2003) 30733084. DOI: https://doi.org/10.1016/S1359-6454(03)00118-6.

[17] T. Al-Samman, G. Gottstein, Materials Science and Engineering: A, 490 (2008) 411-420. DOI: https://doi.org/10.1016/j.msea.2008.02.004.

[18] S. Sandlöbes, I. Schestakow, S.B. Yi, S. Zaefferer, J.Q. Chen, M. Friák, J. Neugebauer, D. Raabe, Materials Science Forum, 690 (2011) 202-205. DOI: 10.4028/www.scientific.net/MSF.690.202.

[19] H. Azzeddine, D. Bradai, Journal of Rare Earths, 31 (2013) 804-810. DOI: https://doi.org/10.1016/S1002-0721(12)60362-7.

[20] D. Elfiad, Y.I. Bourezg, H. Azzeddine, D. Bradai, International Journal of Materials Research, 107 (2016) 315-323. DOI: 10.3139/146.111347.

[21] A. Hanna, H. Azzeddine, R. Lachhab, T. Baudin, A.-L. Helbert, F. Brisset, Y. Huang, D. Bradai, T.G. Langdon, Journal of Alloys and Compounds, 778 (2019) 61-71. DOI: https://doi.org/10.1016/j.jallcom.2018.11.109. 
[22] M. Kaviani, G.R. Ebrahimi, H.R. Ezatpour, Materials Chemistry and Physics, 234 (2019) 245-258. DOI: https://doi.org/10.1016/j.matchemphys.2019.06.010.

[23] S.M. Fatemi, H. Paul, Materials Chemistry and Physics, 257 (2021) 123726. DOI: https://doi.org/10.1016/j.matchemphys.2020.123726.

[24] O. Sitdikov, R. Kaibyshev, T. Sakai, Materials Science Forum, 419-422 (2003) 521-526. DOI: 10.4028/www.scientific.net/MSF.419-422.521.

[25] S.E. Ion, F.J. Humphreys, S.H. White, Acta Metallurgica, 30 (1982) 1909-1919. DOI: https://doi.org/10.1016/0001-6160(82)90031-1.

[26] F.J. Humphreys, M. Hatherly, Chapter 7 - Recrystallization of Single-Phase Alloys, in: F.J. Humphreys, M. Hatherly (Eds.) Recrystallization and Related Annealing Phenomena (Second Edition), Elsevier, Oxford, 2004, pp. 215-IV.

[27] M.R. Barnett, M.D. Nave, C.J. Bettles, Materials Science and Engineering: A, 386 (2004) 205-211. DOI: https://doi.org/10.1016/j.msea.2004.07.030.

[28] T. Abu Leil, N. Hort, W. Dietzel, C. Blawert, Y. Huang, K.U. Kainer, K.P. Rao, Transactions of Nonferrous Metals Society of China, 19 (2009) 40-44. DOI: https://doi.org/10.1016/S1003-6326(08)60225-3.

[29] S. Abdessameud, H. Azzeddine, B. Alili, D. Bradai, Transactions of Nonferrous Metals Society of China, 20 (2010) 2215-2222. DOI: https://doi.org/10.1016/S1003-6326(10)606310 .

[30] T. Al-Samman, Materials Science and Engineering: A, 560 (2013) 561-566. DOI: https://doi.org/10.1016/j.msea.2012.09.102.

[31] J.J. Bhattacharyya, S.R. Agnew, G. Muralidharan, Acta Materialia, 86 (2015) 80-94. DOI: https://doi.org/10.1016/j.actamat.2014.12.009.

[32] Y. Wang, Y. Xin, Q. Liu, Journal of Alloys and Compounds, 666 (2016) 341-345. DOI: https://doi.org/10.1016/j.jallcom.2015.12.253.

[33] J. Su, S. Yue, in: K.N. Solanki, D. Orlov, A. Singh, N.R. Neelameggham (Eds.) Magnesium Technology 2017, Springer International Publishing, Cham, 2017, pp. 547-554.

[34] D. Guan, W.M. Rainforth, L. Ma, B. Wynne, J. Gao, Acta Materialia, 126 (2017) 132144. DOI: https://doi.org/10.1016/j.actamat.2016.12.058.

[35] J.-x. Liu, K. Liu, W.-b. Du, S.-b. Li, Z.-h. Wang, X. Du, C.-c. Sun, Transactions of Nonferrous Metals Society of China, 28 (2018) 2214-2225. DOI: https://doi.org/10.1016/S1003-6326(18)64866-6. 
[36] A. Imandoust, C.D. Barrett, T. Al-Samman, M.A. Tschopp, E. Essadiqi, N. Hort, H. El Kadiri, Metallurgical and Materials Transactions A, 49 (2018) 1809-1829. DOI: $10.1007 / \mathrm{s} 11661-018-4520-8$.

[37] X. Zeng, P. Minárik, P. Dobroň, D. Letzig, K.U. Kainer, S. Yi, Scripta Materialia, 166 (2019) 53-57. DOI: https://doi.org/10.1016/j.scriptamat.2019.02.045.

[38] S.S.A. Shah, D. Wu, R.S. Chen, G.S. Song, Journal of Alloys and Compounds, 805 (2019) 189-197. DOI: https://doi.org/10.1016/j.jallcom.2019.07.086.

[39] A. Hanna, H. Azzeddine, Y. Huang, D. Bradai, J.M. Cabrera, T.G. Langdon, Materials Characterization, 151 (2019) 519-529. DOI: https://doi.org/10.1016/j.matchar.2019.03.040.

[40] Q. Wang, B. Jiang, A. Tang, J. Fu, Z. Jiang, H. Sheng, D. Zhang, G. Huang, F. Pan, Journal of Materials Science \& Technology, 43 (2020) 104-118. DOI: https://doi.org/10.1016/j.jmst.2020.01.018.

[41] K.D. Molodov, T. Al-Samman, D.A. Molodov, G. Gottstein, Acta Materialia, 76 (2014) 314-330. DOI: https://doi.org/10.1016/j.actamat.2014.04.066.

[42] J.H. Kim, B.-C. Suh, T.T.T. Trang, J.H. Hwang, N.J. Kim, Scripta Materialia, 170 (2019) 11-15. DOI: https://doi.org/10.1016/j.scriptamat.2019.05.029.

[43] T. Al-Samman, K.D. Molodov, D.A. Molodov, G. Gottstein, S. Suwas, Acta Materialia, 60 (2012) 537-545. DOI: https://doi.org/10.1016/j.actamat.2011.10.013.

[44] M. Wang, R. Xin, B. Wang, Q. Liu, Materials Science and Engineering: A, 528 (2011) 2941-2951. DOI: https://doi.org/10.1016/j.msea.2010.11.069.

[45] S. Abdessameud, D. Bradai, Canadian Metallurgical Quarterly, 48 (2009) 433-442. DOI: 10.1179/cmq.2009.48.4.433.

[46] A. Hanna, A. Dakhouche, K. Tirsatine, A. Sari, Y. Khereddine, D. Bradai, H. Azzeddine, Metall. Res. Technol., 116 (2019) 109.

[47] W.S.D. Wilcock, P.C. Kauffman, Journal of Power Sources, 66 (1997) 71-75. DOI: https://doi.org/10.1016/S0378-7753(96)02483-4.

[48] K. Yu, H.-q. Xiong, L. Wen, Y.-l. Dai, S.-h. Yang, S.-f. Fan, F. Teng, X.-y. Qiao, Transactions of Nonferrous Metals Society of China, 25 (2015) 1234-1240. DOI: https://doi.org/10.1016/S1003-6326(15)63720-7.

[49] S. Tighiouaret, R. Lachhab, A. Hanna, H. Azzeddine, Y. Huang, T. Baudin, A.-L. Helbert, F. Brisset, D. Bradai, T.G. Langdon, Advanced Engineering Materials, 21 (2019) 1900801. DOI: 10.1002/adem.201900801. 
[50] F. Guerza-Soualah, H. Azzeddine, T. Baudin, A.-L. Helbert, F. Brisset, D. Bradai, Journal of Magnesium and Alloys, 8 (2020) 1198-1207. DOI: https://doi.org/10.1016/j.jma.2020.05.004.

[51] F. Guerza-Soualah, A. Hanna, H. Azzeddine, A.-L. Helbert, F. Brisset, T. Baudin, D. Bradai, Materials Today Communications, 24 (2020) 101239. DOI: https://doi.org/10.1016/j.mtcomm.2020.101239.

[52] W. Habila, H. Azzeddine, B. Mehdi, K. Tirsatine, T. Baudin, A.-L. Helbert, F. Brisset, S. Gautrot, M.-H. Mathon, D. Bradai, Materials Characterization, 147 (2019) 242-252. DOI: https://doi.org/10.1016/j.matchar.2018.11.010.

[53] Y. Mikami, K. Oda, M. Kamaya, M. Mochizuki, Materials Science and Engineering: A, 647 (2015) 256-264. DOI: https://doi.org/10.1016/j.msea.2015.09.004.

[54] R. Hielscher, H. Schaeben, Journal of Applied Crystallography, 41 (2008) 1024-1037. DOI: $10.1107 / \mathrm{s} 0021889808030112$.

[55] J.-H. Cho, A.D. Rollett, K.H. Oh, Metallurgical and Materials Transactions A, 36 (2005) 3427-3438. DOI: 10.1007/s11661-005-0016-4.

[56] C. Drouven, I. Basu, T. Al-Samman, S. Korte-Kerzel, Materials Science and Engineering: A, 647 (2015) 91-104. DOI: https://doi.org/10.1016/j.msea.2015.08.090.

[57] C.D. Barrett, A. Imandoust, A.L. Oppedal, K. Inal, M.A. Tschopp, H. El Kadiri, Acta Materialia, 128 (2017) 270-283. DOI: https://doi.org/10.1016/j.actamat.2017.01.063.

[58] H. Watanabe, T. Mukai, K. Ishikawa, Journal of Materials Processing Technology, 182 (2007) 644-647. DOI: https://doi.org/10.1016/j.jmatprotec.2006.08.010.

[59] H.-J. Bunge, Texture Analysis in Materials Science, 1st edition ed., ButterworthHeinemann, 1982.

[60] J. Victoria-Hernandez, S. Yi, J. Bohlen, G. Kurz, D. Letzig, Journal of Alloys and Compounds, 616 (2014) 189-197. DOI: https://doi.org/10.1016/j.jallcom.2014.07.083.

[61] Z. Shi, F. Cao, G.-L. Song, M. Liu, A. Atrens, Corrosion Science, 76 (2013) 98-118. DOI: https://doi.org/10.1016/j.corsci.2013.06.032.

[62] T. Zhang, Y. Shao, G. Meng, Z. Cui, F. Wang, Corrosion Science, 53 (2011) 1960-1968. DOI: https://doi.org/10.1016/j.corsci.2011.02.015.

[63] D. Daloz, P. Steinmetz, G. Michot, Corrosion, 53 (1997) 944-954. DOI: $10.5006 / 1.3290279$.

[64] H. Azzeddine, A. Hanna, A. Dakhouche, L. Rabahi, N. Scharnagl, M. Dopita, F. Brisset, A.-L. Helbert, T. Baudin, Journal of Alloys and Compounds, 829 (2020) 154569. DOI: https://doi.org/10.1016/j.jallcom.2020.154569. 
[65] Y. Song, E.-H. Han, K. Dong, D. Shan, C.D. Yim, B.S. You, Corrosion Science, 88 (2014) 215-225. DOI: https://doi.org/10.1016/j.corsci.2014.07.034.

[66] Y. Ateba Betanda, A.-L. Helbert, F. Brisset, M.-H. Mathon, T. Waeckerlé, T. Baudin, Materials Science and Engineering: A, 614 (2014) 193-198. DOI: https://doi.org/10.1016/j.msea.2014.07.037.

[67] W. Pantleon, Scripta Materialia, 58 (2008) 994-997. DOI: https://doi.org/10.1016/j.scriptamat.2008.01.050.

[68] S.S. Hazra, A.A. Gazder, E.V. Pereloma, Materials Science and Engineering: A, 524 (2009) 158-167. DOI: https://doi.org/10.1016/j.msea.2009.06.033.

[69] H. Azzeddine, K. Tirsatine, T. Baudin, M.-H. Mathon, A.-L. Helbert, F. Brisset, D. Bradai, Materials Chemistry and Physics, 201 (2017) 408-415. DOI: https://doi.org/10.1016/j.matchemphys.2017.08.063.

[70] S.R. Agnew, M.H. Yoo, C.N. Tomé, Acta Materialia, 49 (2001) 4277-4289. DOI: https://doi.org/10.1016/S1359-6454(01)00297-X.

[71] M.T. Pérez-Prado, J.A. del Valle, J.M. Contreras, O.A. Ruano, Scripta Materialia, 50 (2004) 661-665. DOI: https://doi.org/10.1016/j.scriptamat.2003.11.014.

[72] D. Liu, Z.-y. Liu, E.-d. Wang, Transactions of Nonferrous Metals Society of China, 25 (2015) 3585-3594. DOI: https://doi.org/10.1016/S1003-6326(15)63999-1.

[73] L.W.F. Mackenzie, M. Pekguleryuz, Materials Science and Engineering: A, 480 (2008) 189-197. DOI: https://doi.org/10.1016/j.msea.2007.07.003.

[74] X.-y. Yang, Z.-s. Ji, H. Miura, T. Sakai, Transactions of Nonferrous Metals Society of China, 19 (2009) 55-60. DOI: https://doi.org/10.1016/S1003-6326(08)60228-9.

[75] Y. Pei, A. Godfrey, J. Jiang, Y.B. Zhang, W. Liu, Q. Liu, Materials Science and Engineering: A, 550 (2012) 138-145. DOI: https://doi.org/10.1016/j.msea.2012.04.046.

[76] P. Chen, B. Li, D. Culbertson, Y. Jiang, in: D. Orlov, V. Joshi, K.N. Solanki, N.R. Neelameggham (Eds.) Magnesium Technology 2018, Springer International Publishing, Cham, 2018, pp. 193-198.

[77] S. Niknejad, S. Esmaeili, N.Y. Zhou, Acta Materialia, 102 (2016) 1-16. DOI: https://doi.org/10.1016/j.actamat.2015.09.026.

[78] Y. Chino, K. Kimura, M. Hakamada, M. Mabuchi, Materials Science and Engineering: A, 485 (2008) 311-317. DOI: https://doi.org/10.1016/j.msea.2007.07.076.

[79] L.-1. Guo, F. Fujita, Transactions of Nonferrous Metals Society of China, 28 (2018) 1094-1102. DOI: https://doi.org/10.1016/S1003-6326(18)64745-4. 
[80] Y.N. Wang, J.C. Huang, Materials Chemistry and Physics, 81 (2003) 11-26. DOI: https://doi.org/10.1016/S0254-0584(03)00168-8.

[81] L.W.F. Mackenzie, B. Davis, F.J. Humphreys, G.W. Lorimer, Materials Science and Technology, 23 (2007) 1173-1180. DOI: 10.1179/174328407X226509.

[82] E.A. Ball, P.B. Prangnell, Scripta Metallurgica et Materialia, 31 (1994) 111-116. DOI: https://doi.org/10.1016/0956-716X(94)90159-7.

[83] J. Bohlen, M.R. Nürnberg, J.W. Senn, D. Letzig, S.R. Agnew, Acta Materialia, 55 (2007) 2101-2112. DOI: https://doi.org/10.1016/j.actamat.2006.11.013.

[84] M.T. Pérez-Prado, O.A. Ruano, Scripta Materialia, 48 (2003) 59-64. DOI: https://doi.org/10.1016/S1359-6462(02)00346-9.

[85] G.L. Song, A. Atrens, Advanced Engineering Materials, 1 (1999) 11-33. DOI: 10.1002/(sici)1527-2648(199909)1:1<11::aid-adem11>3.0.co;2-n.

[86] B.R. Sunil, A.A. Kumar, T.S. Sampath Kumar, U. Chakkingal, Materials Science and Engineering: C, 33 (2013) 1607-1615. DOI: https://doi.org/10.1016/j.msec.2012.12.095.

[87] B. Ratna Sunil, T.S. Sampath Kumar, U. Chakkingal, V. Nandakumar, M. Doble, V. Devi Prasad, M. Raghunath, Materials Science and Engineering: C, 59 (2016) 356-367. DOI: https://doi.org/10.1016/j.msec.2015.10.028.

[88] D.R. Lopes, C.L.P. Silva, R.B. Soares, P.H.R. Pereira, A.C. Oliveira, R.B. Figueiredo, T.G. Langdon, V.F.C. Lins, Advanced Engineering Materials, 21 (2019) 1900391. DOI: 10.1002/adem.201900391.

[89] H.-y. Niu, K.-k. Deng, K.-b. Nie, C.-j. Wang, W. Liang, Y.-c. Wu, Materials Chemistry and Physics, 249 (2020) 123131. DOI: https://doi.org/10.1016/j.matchemphys.2020.123131.

[90] C.L.P. Silva, R.B. Soares, P.H.R. Pereira, R.B. Figueiredo, V.F.C. Lins, T.G. Langdon, Advanced Engineering Materials, 21 (2019) 1801081. DOI: 10.1002/adem.201801081.

[91] E. Aghion, G. Golub, Production Technologies of Magnesium, Magnesium Technology: Metallurgy, Design Data, Applications, Springer Berlin Heidelberg, Berlin, Heidelberg, 2006, pp. 29-62.

[92] A. Kocijan, Materiali in Tehnologije, 45 (2011) 91-94.

[93] Y. Luo, Y. Deng, L. Guan, L. Ye, X. Guo, A. Luo, Corrosion Science, 164 (2020) 108338. DOI: https://doi.org/10.1016/j.corsci.2019.108338.

[94] R. Xin, B. Li, L. Li, Q. Liu, Materials \& Design, 32 (2011) 4548-4552. DOI: https://doi.org/10.1016/j.matdes.2011.04.031. 


\section{Figure caption}

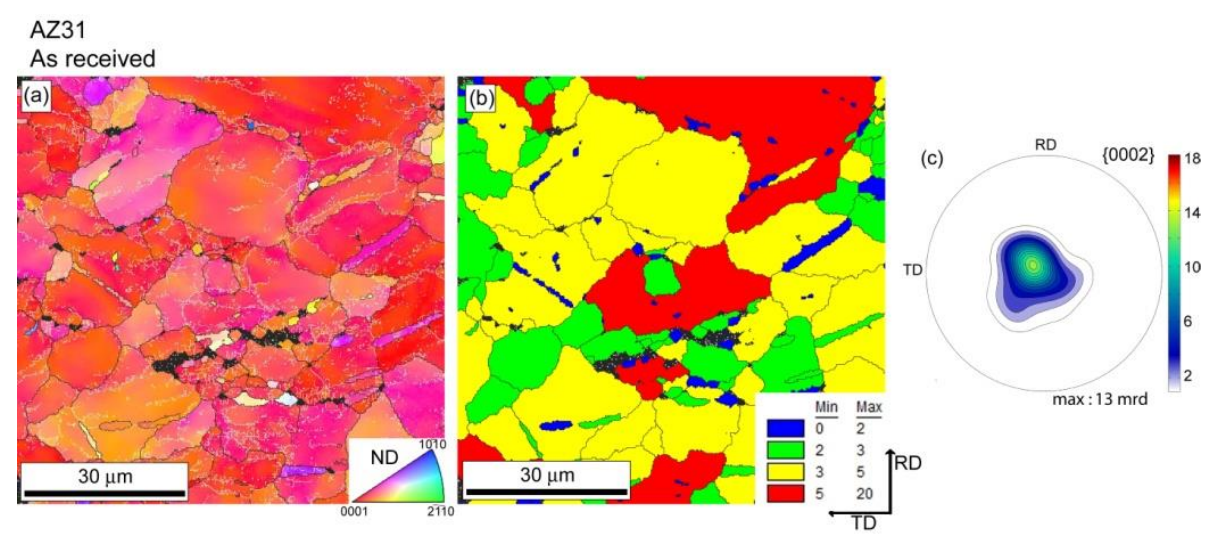

Fig. 1. (a) ND-IPF map, (b) GOS map and (c) recalculated basal $\{0002\}$ pole figure of the asreceived AZ31 alloy. 


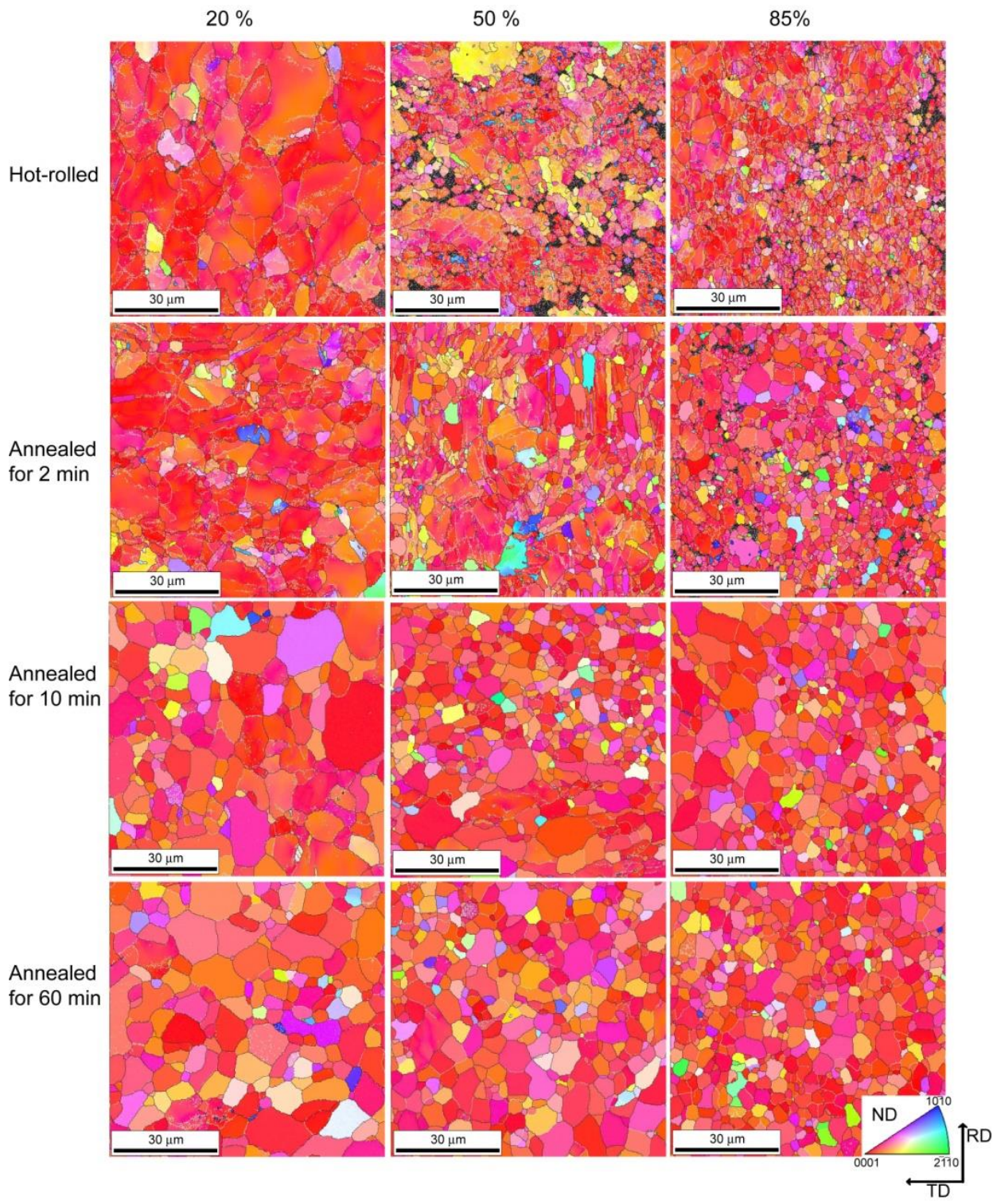

Fig. 2. ND-IPF map of the AZ31 alloy after hot rolling up to 20, 50 and $85 \%$ of thickness reduction and annealing at $350{ }^{\circ} \mathrm{C}$ for 2,10 and $60 \mathrm{~min}$, respectively. 

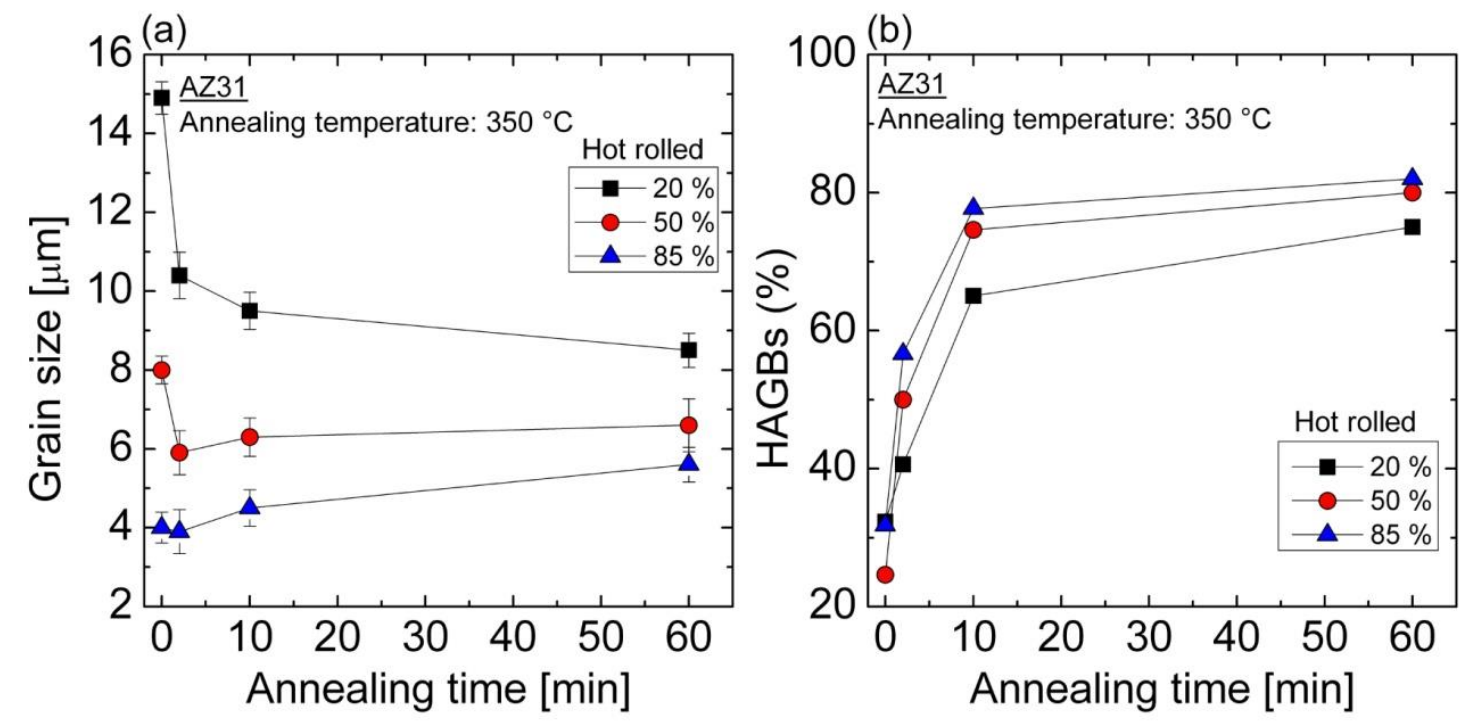

Fig. 3. Evolution of (a) grain size and (b) fraction of HAGBs as a function of annealing time of the hot-rolled AZ31 alloy up to 20,50 and $85 \%$ of thickness reduction, respectively.

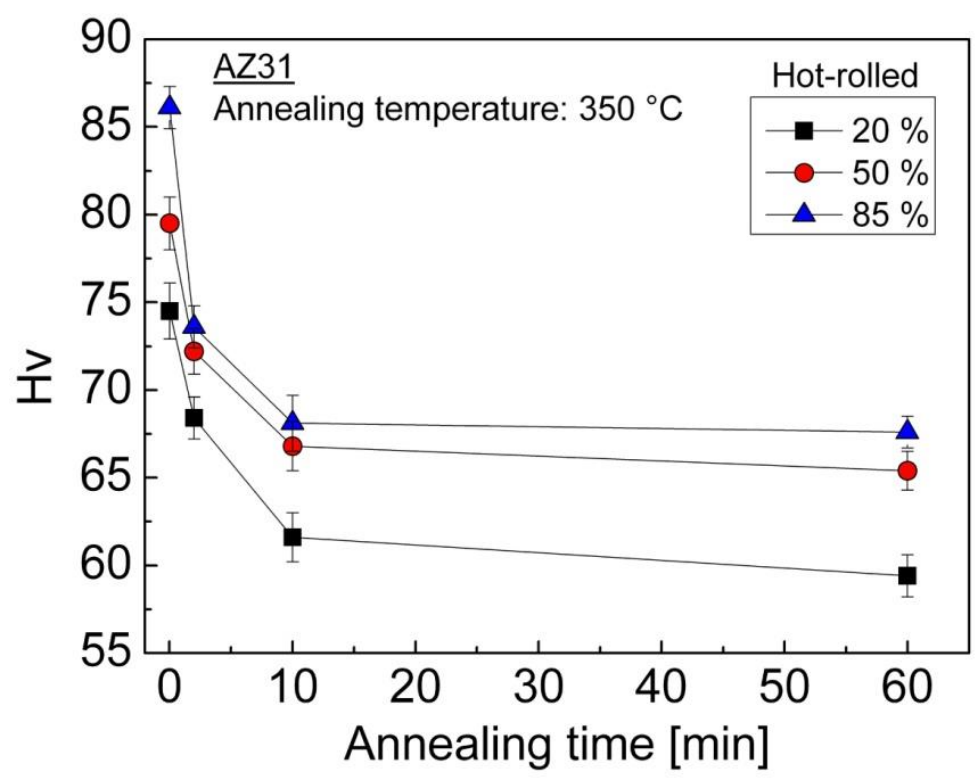

Fig. 4. Evolution of microhardness as a function of annealing time of the hot-rolled AZ31 alloy up to 20,50 and $85 \%$ of thickness reduction, respectively. 


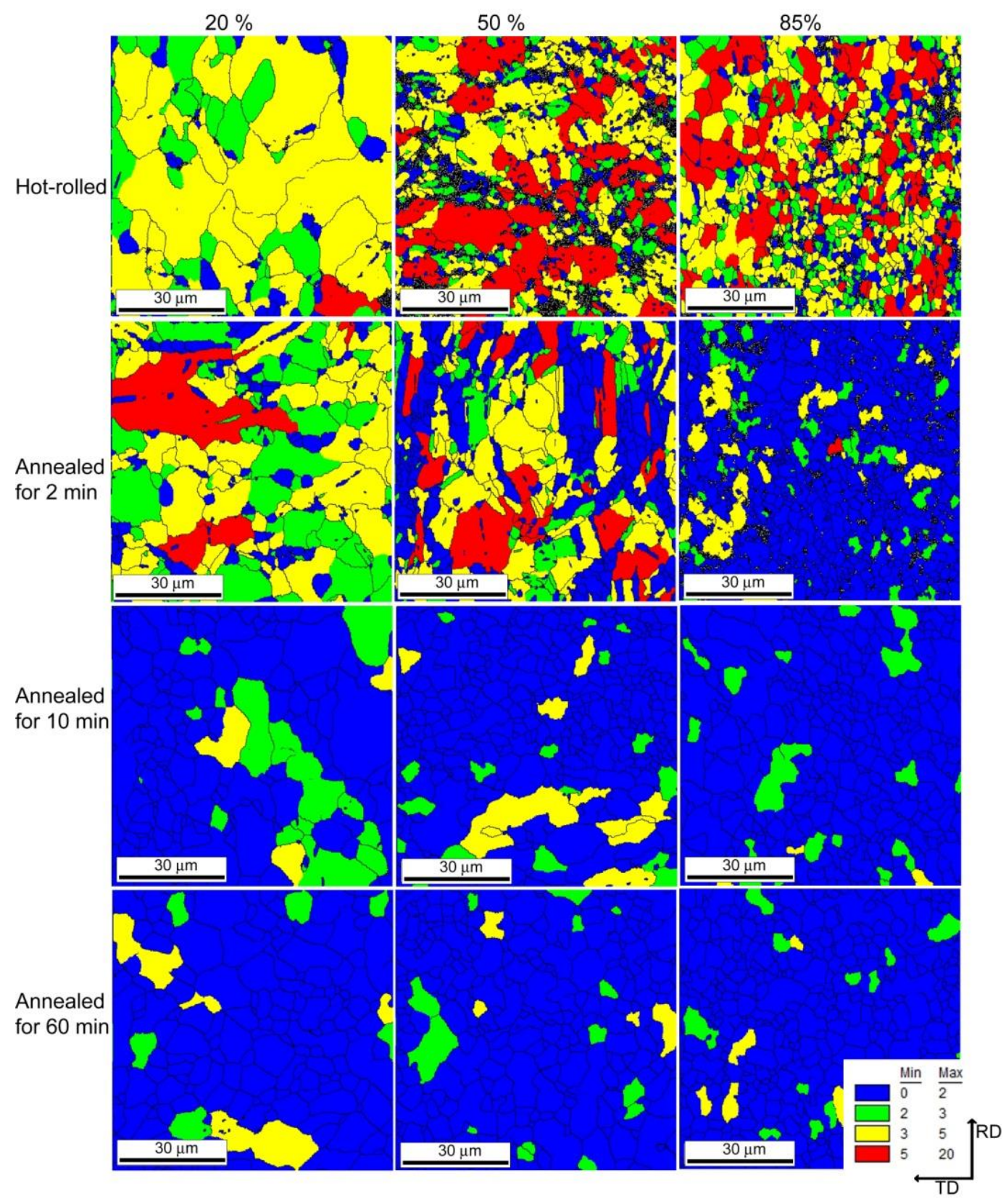

Fig. 5. GOS maps of the hot-rolled AZ31 alloy up to 20, 50 and $85 \%$ of thickness reduction and annealing at $350{ }^{\circ} \mathrm{C}$ for 2,10 and $60 \mathrm{~min}$, respectively. 


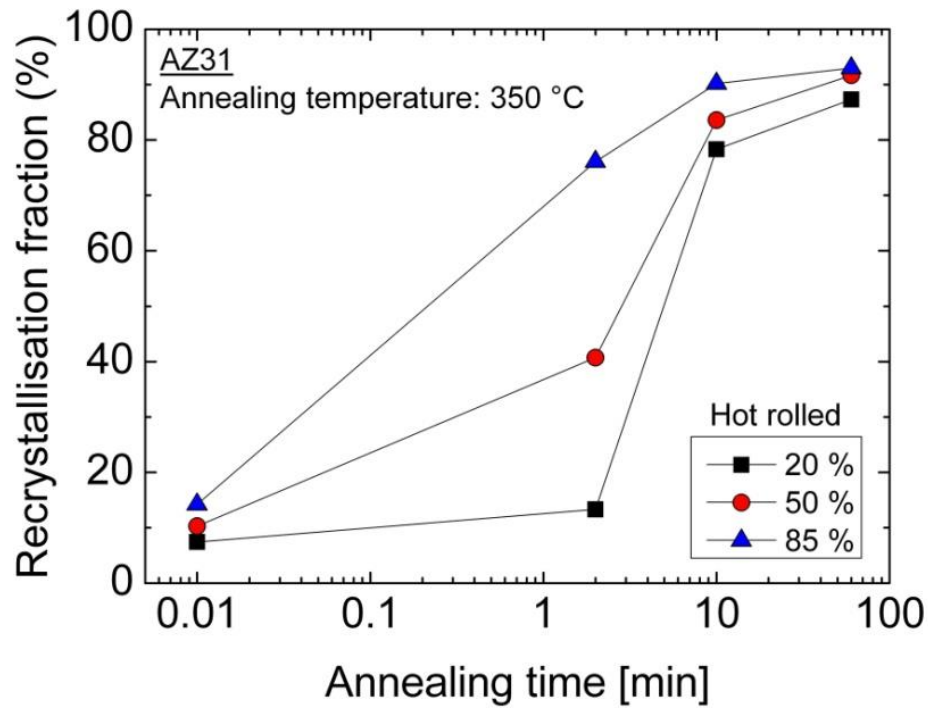

Fig. 6. Evolution of the recrystallization fraction as a function of annealing time of the hotrolled AZ31 alloy up to 20,50 and $85 \%$ of thickness reduction, respectively. 


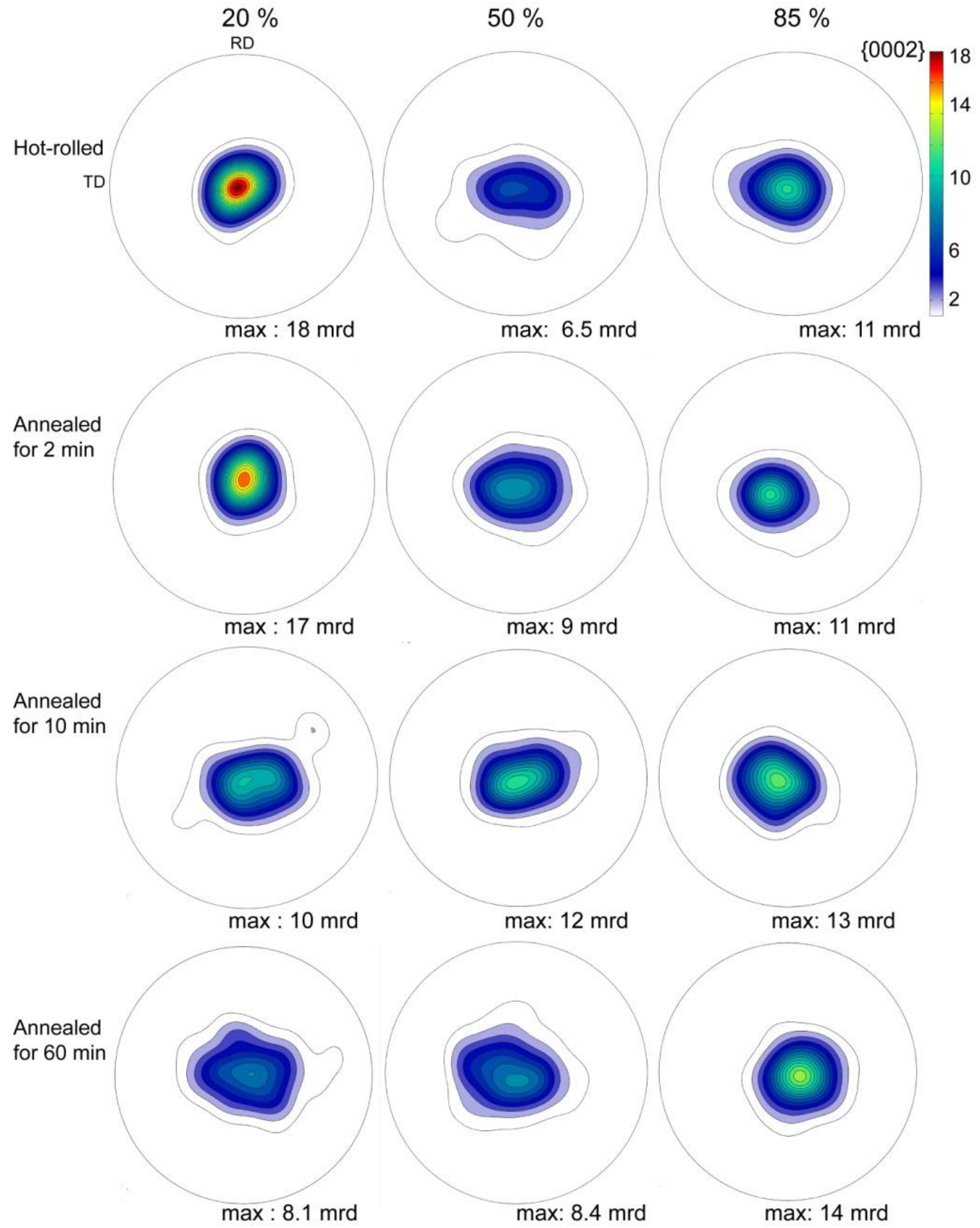

Fig. 7. Recalculated basal $\{0002\}$ pole figure of the hot-rolled and the annealed AZ31 alloy. 


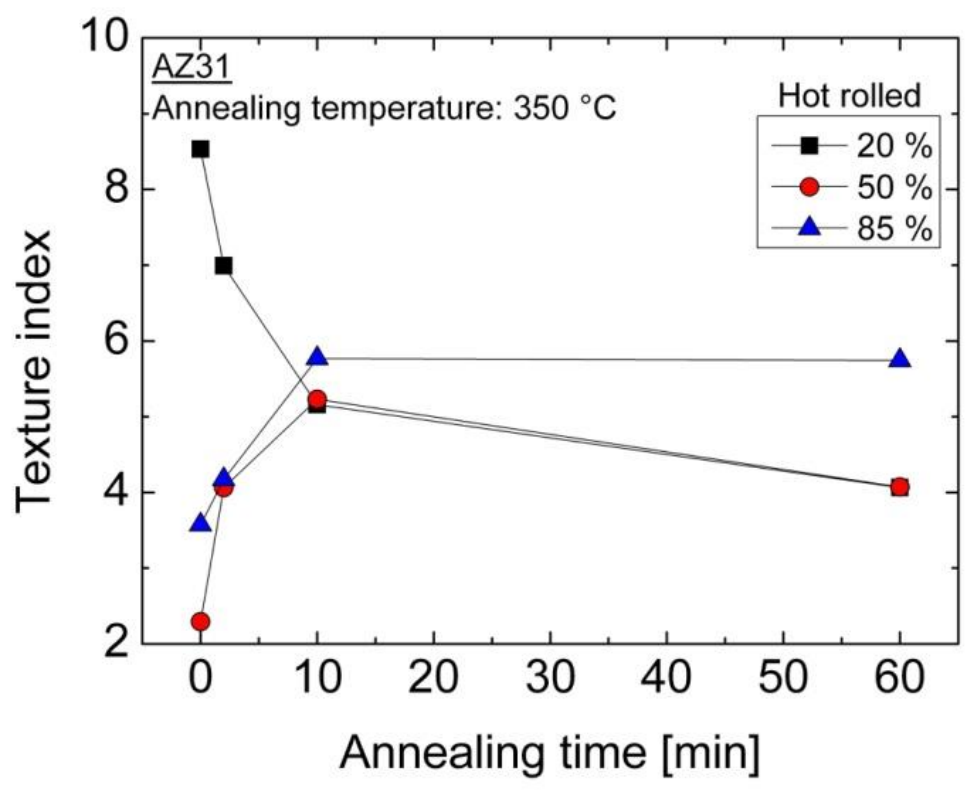

Fig. 8. Evolution of the texture index as a function of annealing time of the hot-rolled and the annealed AZ31 alloy.

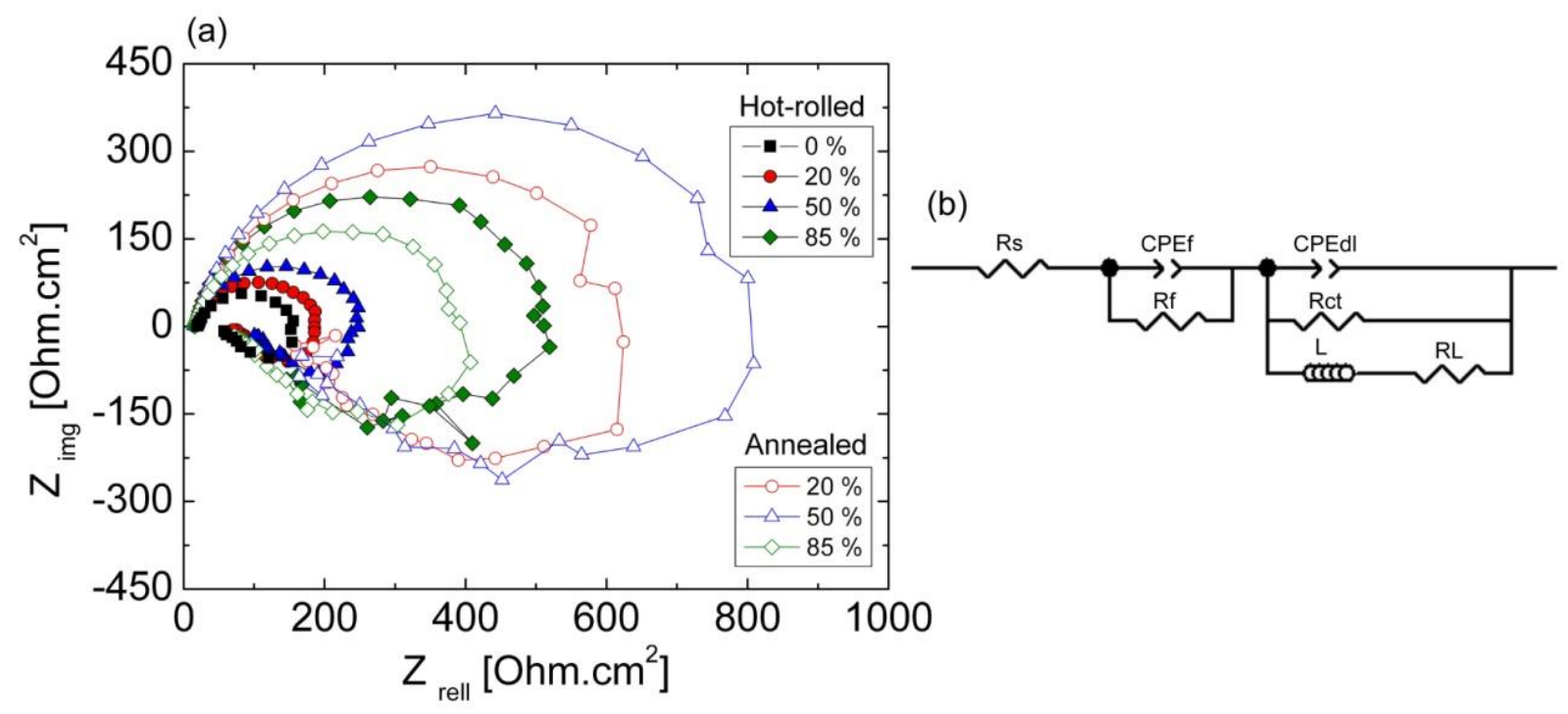

Fig. 9. (a) Nyquist plots and (b) the equivalent circuit of the as-received, hot-rolled and annealed AZ31 alloy in seawater. 

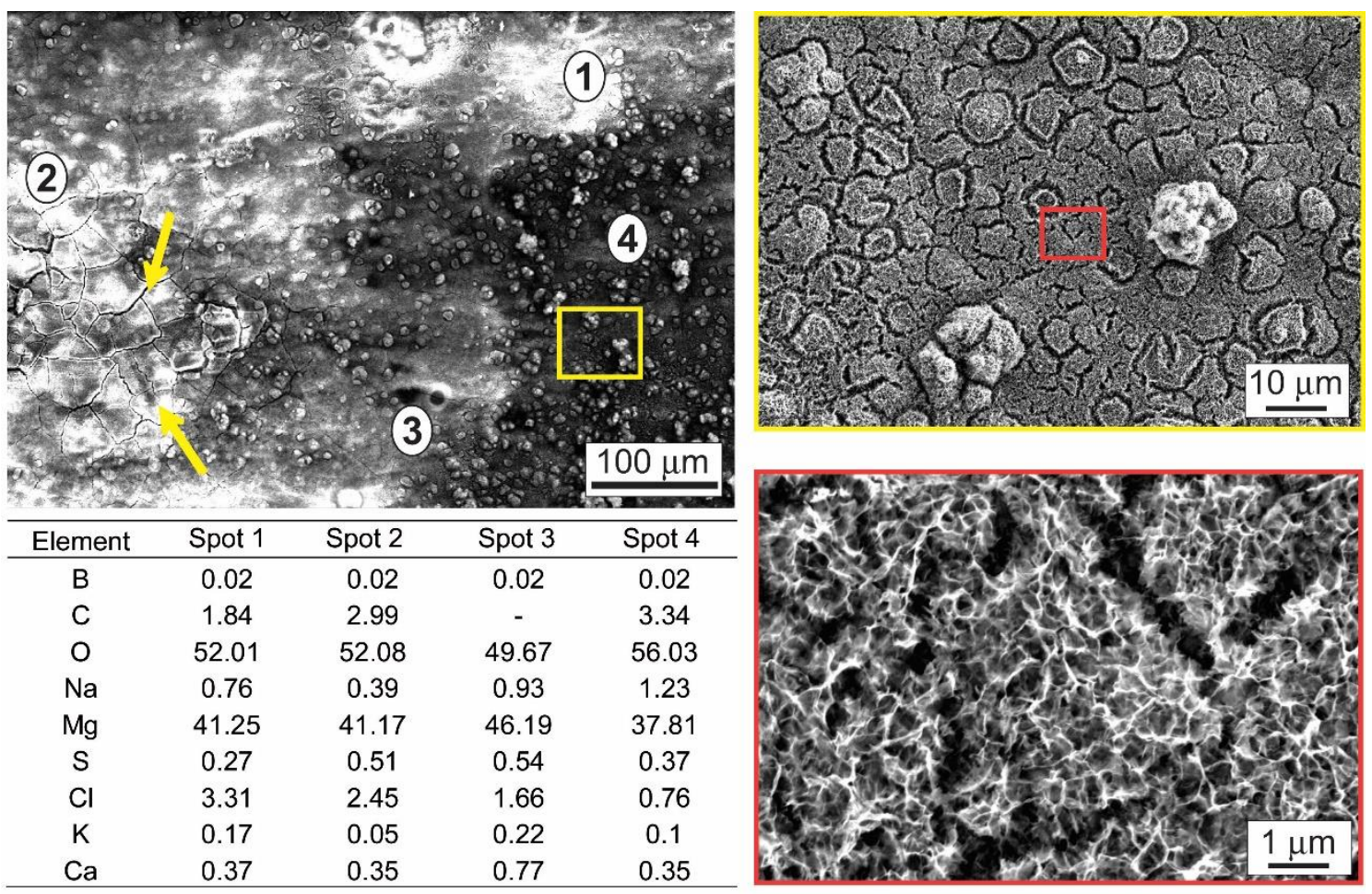

Fig. 10. SEM micrograph with different resolutions and the corresponding EDS analysis in weight percentage of the as-received AZ31 alloy after immersion in seawater for $3 \mathrm{~h}$.
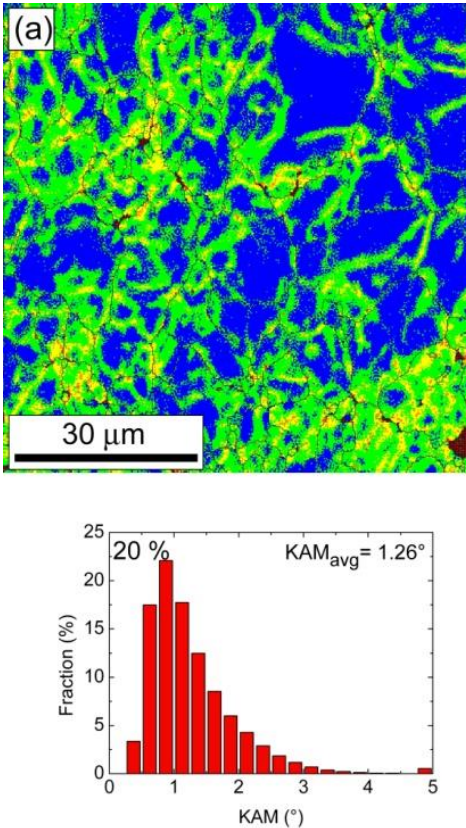
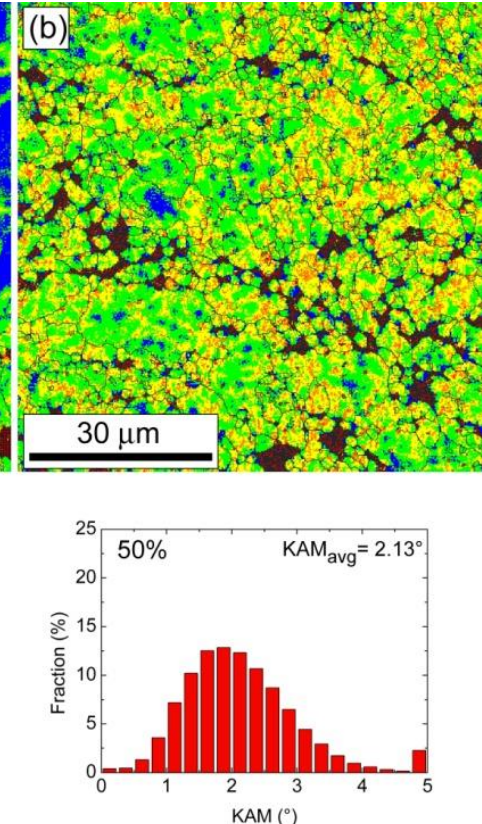
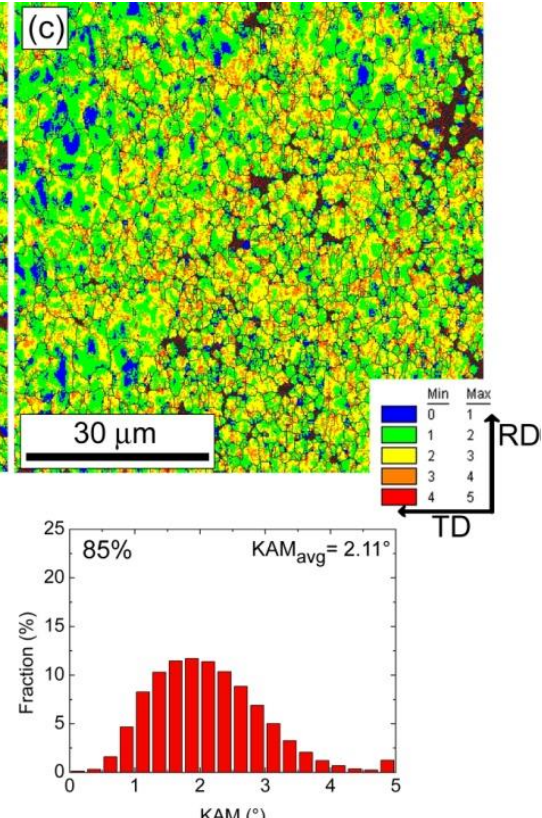

Fig. 11. KAM maps and their corresponding distributions of the hot-rolled AZ31 alloy for: (a) 20, (b) 50 and (c) $85 \%$ of thickness reduction. 

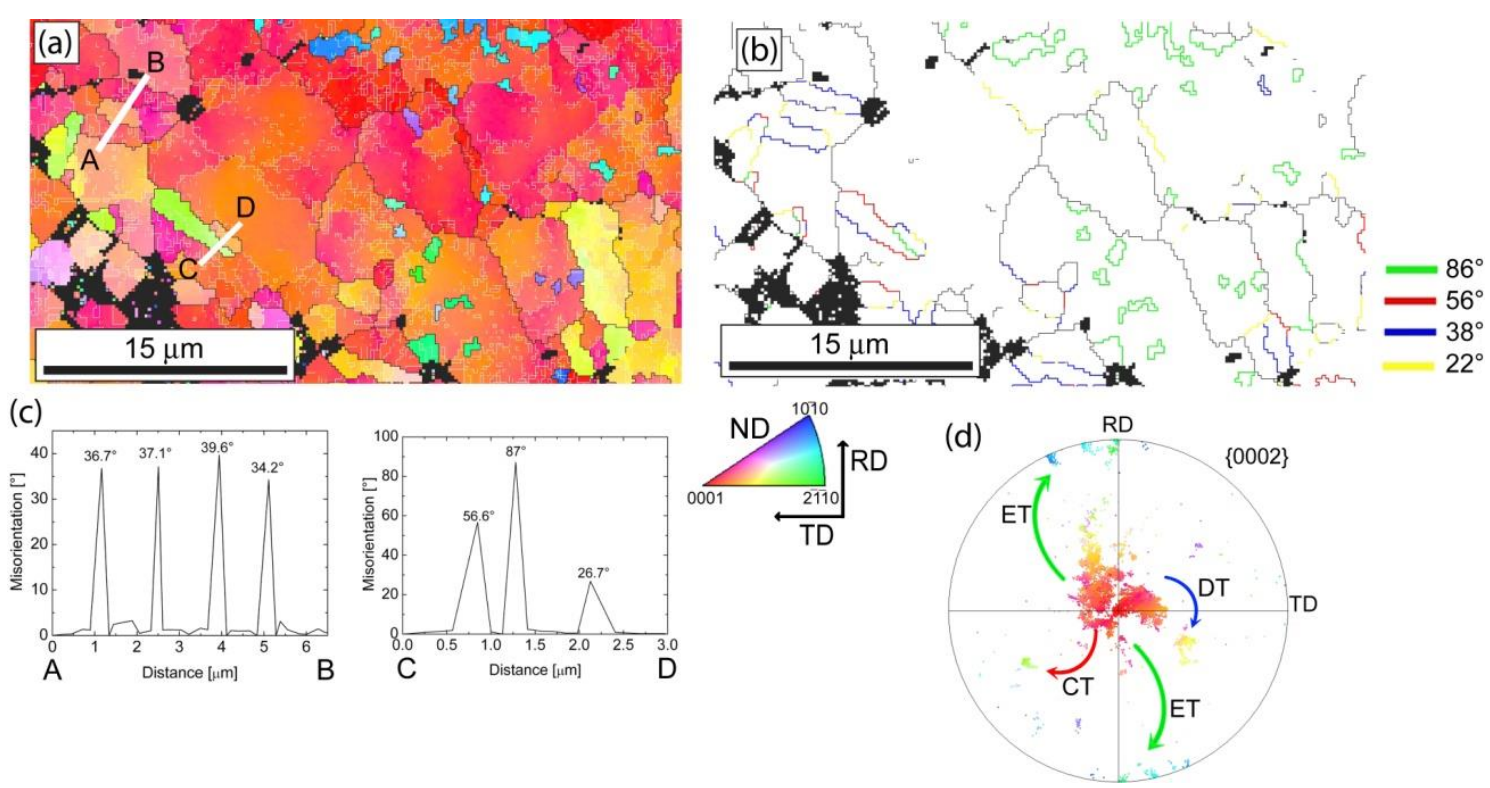

Fig. 12. (a) ND-IPF map of selected region of the $50 \%$ hot-rolled sample, (b) map showing the different twins, (c) misorientation profile along segments from A to B and C to D and (d) the corresponding $\{0002\}$ pole figure indicates the orientation between grains and twins. ET, CT and DT correspond to extension, contraction and double twins, respectively.

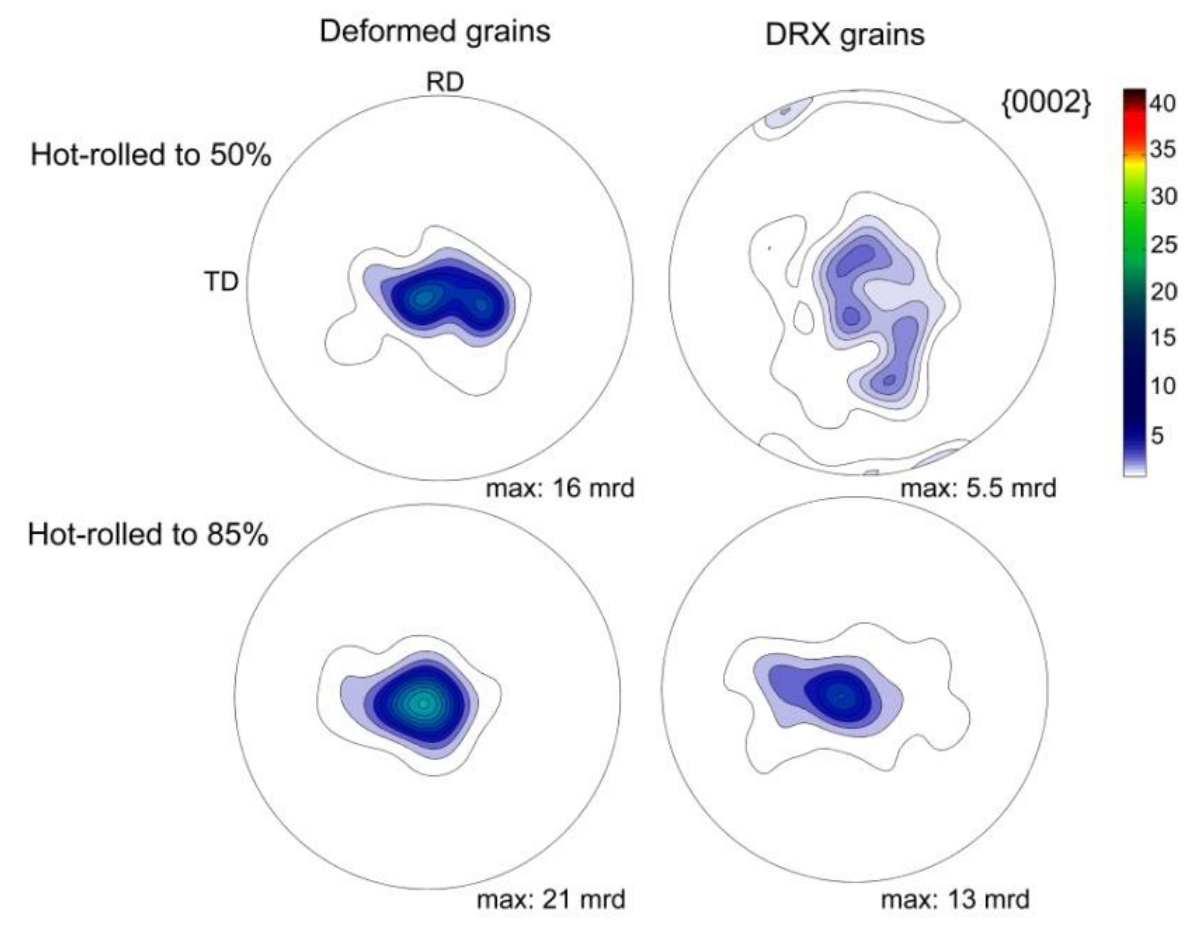

Fig. 13. Recalculated $\{0002\}$ pole figure for the deformed and dynamically recrystallized grains of the 50 and $85 \%$ hot-rolled samples, respectively. 


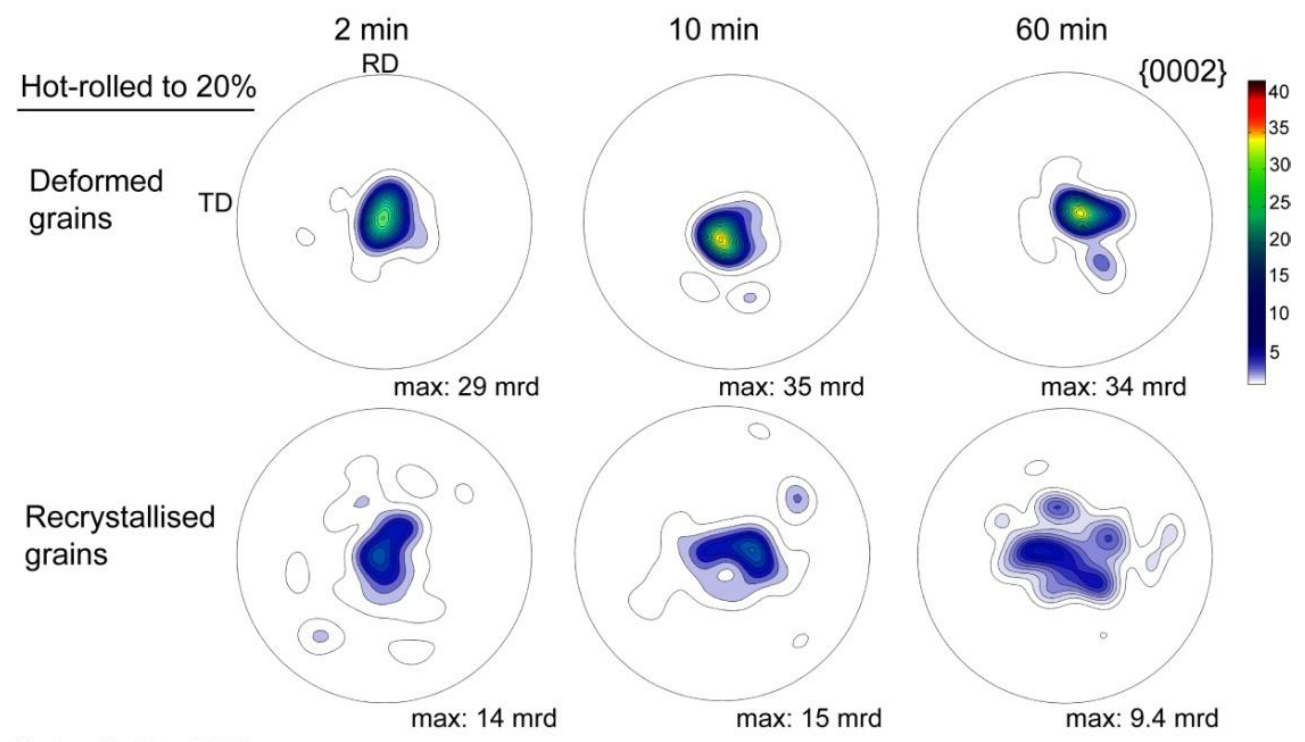

Hot-rolled to $50 \%$
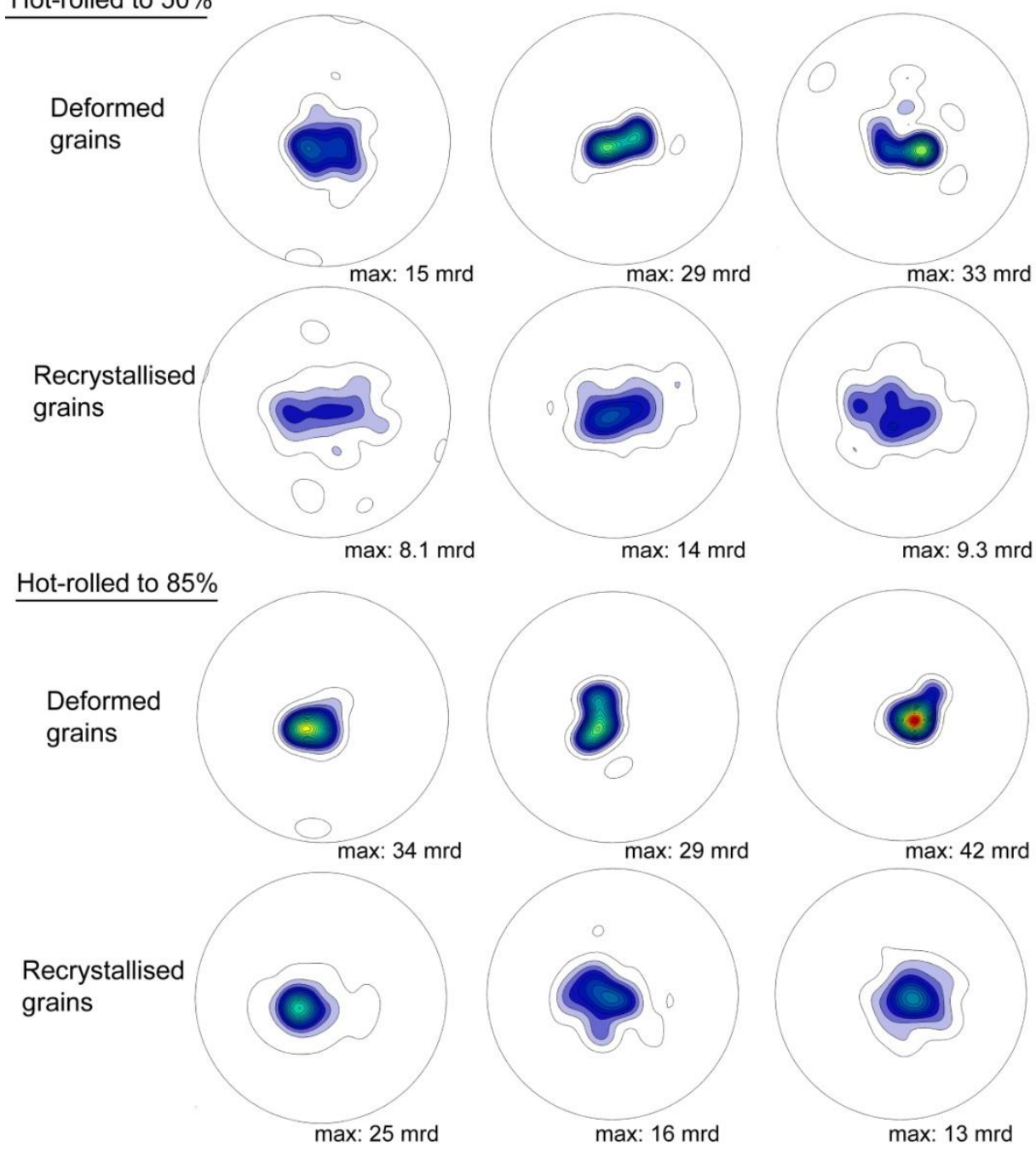

Fig. 14. Recalculated $\{0002\}$ pole figure for the deformed and recrystallized grains as a function of annealing time of the hot-rolled AZ31 alloy. 


\section{Table caption}

Table 1. Chemical composition (in weight percentage) of AZ31 alloy.

\begin{tabular}{ccccccc}
\hline $\mathrm{Al}$ & $\mathrm{Zn}$ & $\mathrm{Mn}$ & $\mathrm{Ca}$ & $\mathrm{Cu}$ & $\mathrm{Fe}$ & $\mathrm{Mg}$ \\
\hline 3.45 & 0.98 & 0.28 & 0.002 & 0.002 & 0.004 & Balance
\end{tabular}

Table 2. Electrochemical parameters obtained from the fits of the experimental Nyquist data of the AZ31 samples in seawater.

\begin{tabular}{|c|c|c|c|c|c|c|c|c|c|c|}
\hline & \multirow[t]{2}{*}{$\mathrm{R}_{\mathrm{s}}\left(\Omega \cdot \mathrm{cm}^{2}\right)$} & \multicolumn{2}{|c|}{$\mathrm{CPE}_{\mathrm{f}}\left(\mathrm{F} . \mathrm{cm}^{-2}\right)$} & \multirow[t]{2}{*}{$\mathrm{R}_{\mathrm{f}}\left(\Omega \cdot \mathrm{cm}^{2}\right)$} & \multicolumn{2}{|c|}{$\mathrm{CPE}_{\mathrm{dl}}\left(\mathrm{F} . \mathrm{cm}^{-2}\right)$} & \multirow[t]{2}{*}{$\mathrm{R}_{\mathrm{ct}}\left(\Omega . \mathrm{cm}^{2}\right)$} & \multirow[t]{2}{*}{$\mathrm{L}\left(\mathrm{H} \cdot \mathrm{cm}^{-2}\right)$} & \multirow[t]{2}{*}{$\mathrm{R}_{\mathrm{L}}\left(\Omega \cdot \mathrm{cm}^{2}\right)$} & \multirow[t]{2}{*}{$\mathrm{R}_{\mathrm{p}}\left(\Omega . \mathrm{cm}^{2}\right)$} \\
\hline & & $Y\left(\times 10^{-4}\right)$ & $\mathrm{n}$ & & $Y\left(\times 10^{-5}\right)$ & $\mathrm{n}$ & & & & \\
\hline \multicolumn{11}{|c|}{ Hot-rolled } \\
\hline $0 \%$ & 18.04 & 16 & 0.48 & 3.12 & 8.4 & 0.87 & 137.8 & 81.06 & 56.4 & 76.31 \\
\hline $20 \%$ & 11.96 & 7 & 0.31 & 5.4 & 8.45 & 0.89 & 176.8 & 97.62 & 94.53 & 109.08 \\
\hline $50 \%$ & 16.55 & 100 & 0.35 & 6.88 & 5.07 & 0.98 & 230.8 & 189.7 & 141.7 & 161.02 \\
\hline $85 \%$ & 14.7 & 40 & 0.39 & 8.51 & 2.8 & 0.95 & 466.3 & 1111 & 154.4 & 174.84 \\
\hline \multicolumn{11}{|c|}{$\underline{\text { Annealed }}$} \\
\hline $20 \%$ & 13.79 & 1.9 & 0.52 & 15.17 & 4.27 & 0.92 & 611.2 & 315.2 & 199.5 & 223.62 \\
\hline $50 \%$ & 14.55 & 1.9 & 0.6 & 64.98 & 4.03 & 0.96 & 710.2 & 533.5 & 201.5 & 264.13 \\
\hline $85 \%$ & 14.21 & 21 & 0.5 & 7.38 & 4.96 & 0.91 & 376.7 & 178.9 & 76.81 & 96.92 \\
\hline
\end{tabular}


Table 3. Fraction (F) of different twins identified in the hot-rolled AZ31 samples (from Fig. 2).

\begin{tabular}{ccccc}
\hline Twin mode & $\begin{array}{c}\text { Misorientation } \\
\text { (Angle/Axis) }\end{array}$ & & \multicolumn{3}{c}{$\mathrm{F}(\%)$} \\
& & $20 \%$ hot- & $50 \%$ hot- & $85 \%$ hot- \\
& & rolled & rolled & rolled \\
\cline { 3 - 5 }$\{10 \overline{\mathbf{1}} 2\}$ extension twin & $8^{\circ} \pm 8^{\circ}<11 \overline{2} 0>$ & 1.8 & 5.1 & 1.5 \\
$\{10 \overline{\mathbf{1}} 1\}$ contraction twin & $56^{\circ} \pm 8^{\circ}<11 \overline{2} 0>$ & 1.1 & 1.3 & 1.5 \\
$\{10 \overline{\mathbf{1}} 1\}\{10 \overline{\mathbf{1}} 2\}$ double twin & $38^{\circ} \pm 8^{\circ}<11 \overline{2} 0>$ & 1.4 & 2.4 & 1.7 \\
$\{10 \overline{\mathbf{1}} 3\}\{10 \overline{\mathbf{1}} 2\}$ double twin & $22^{\circ} \pm 8^{\circ}<11 \overline{2} 0>$ & 1.1 & 2.0 & 3.4 \\
\hline
\end{tabular}

